\title{
Spectroelectrochemical sensing: current trends and challenges
}

\author{
Jesus Garoz-Ruiz, Juan Victor Perales-Rondon, Aranzazu Heras, Alvaro Colina* \\ Department of Chemistry, Universidad de Burgos, Pza. Misael Bañuelos s/n, E-09001 Burgos, Spain
}

Received: ((will be filled in by the editorial sttaff))

Accepted: ((will be filled in by the editorial sttaff))

\begin{abstract}
Spectroelectrochemistry (SEC) has been used for more than 50 years, but this set of techniques has not been widely used for quantitative analysis. For many years, no commercial instruments were available, which made very difficult to spread the use of SEC. Nowadays, only the creativity of the researchers is required to exploit the capabilities of SEC. This review is written with the aim of showing the potential of SEC, mainly for analytical chemistry. Here, we explain what SEC is, how analytical responses can be obtained, why these techniques are useful for sensors, with a brief description of its advantages in use, and, finally, we try to show the challenges that must be addressed in the next years. SEC can resolve interesting analytical problems using the high amount of data provided by this intrinsic trilinear technique. Given the quantitative analysis point of view of this review, the discussion of the SEC techniques is focused on UV/Vis absorption, photoluminescence and Raman SEC.
\end{abstract}

Keywords: Spectroelectrochemistry, Sensors, UV/Vis absorption, Photoluminescence, Raman

DOI: 10.1002/elan.((will be filled in by the editorial sttaff))

\section{What}

Instrumental techniques provide fundamental information about a chemical system to understand reactions and to determine compounds in complex mixtures and matrices. Moreover, a better description of the chemical systems is obtained if information of different nature is extracted during an experiment. Therefore, the successful marriage of analytical techniques allows researchers to obtain interesting results that facilitate the understanding of chemical systems. For these reasons, the importance of spectroelectrochemistry (SEC) must be highlighted. A single SEC experiment provides simultaneous electrochemical and spectroscopic information about a chemical system, allowing the study of a wide range of processes from, at least, two different points of view [1-26]. Furthermore, the sum of the two types of information is not a simple addition, providing a synergistic effect between optical and electrical signals that helps to explain the electrode process.

As can be deduced, different electrochemical techniques can be used and different spectral regions can be analyzed, depending on the system studied and the desired information to be obtained [1-26]. All these factors highlight the usefulness and versatility of SEC.
Actually, SEC should be considered as a set of different techniques. In fact, each combination of electrochemical and spectroscopic techniques yields a new technique in itself, Figure 1. In general, the most popular combinations are UV/Vis absorption SEC [3,79,13,20,21,23,24,26], fluorescence SEC [5,8-11], Raman SEC $[3,4,8,9,15,27,28]$, IR absorption SEC $[9,21,24,29-$ 34], EPR SEC [3,9] and NMR SEC [6,35-39]. All these techniques have been commonly used to study a wide number of chemical systems, providing a huge amount of information about complex electrochemical processes $[8,23,26,31,35]$.

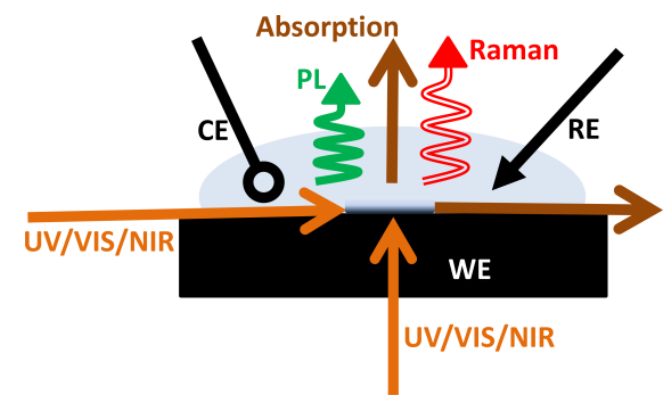

Fig. 1. Schematic view of different types of SEC measurements. Orange arrow: incident light beam. Brown arrow: transmitted light beam. Green arrow: emitted photon. Red arrow: Raman photon. Black rectangle: WE. Black circumference: CE. Black arrow: RE 
Alvaro Colina received his B.S. in Chemistry from Universidad de Valladolid and his Ph.D. in Chemistry from Universidad de Burgos, Spain, where he is working as associated professor. His research interests are devoted to the development of new multiresponse instrumental techniques. Particularly, he has developed a number of different SEC techniques and devices that have been applied in the characterization of materials, study of reaction mechanisms and for analytical purposes.

Aranzazu Heras received a BS in Chemistry and a PhD in Chemistry from Universidad de Burgos (Spain). She is associate professor in Analytical Chemistry from 1997. Her research interests include different aspects related to SEC (UV-Vis-NIR, photoluminescence, Raman), from design and development of new devices to applications of this technique in analysis, characterization of organic, inorganic and nanomaterials, and in the study of different reaction mechanisms.

Juan V. Perales-Rondon received his B.S. in Chemistry from Universidad de Los Andes (Venezuela) and his Ph.D. in Electrochemistry from the Universidad de Alicante (Spain), working in electrocatalysis, in understanding the mechanism of formic acid oxidation on $\mathrm{Pt}$ electrodes. Then he moved to the Universidad de Burgos to work in the SEC field and the development of new SEC devices. Recently he is working in the

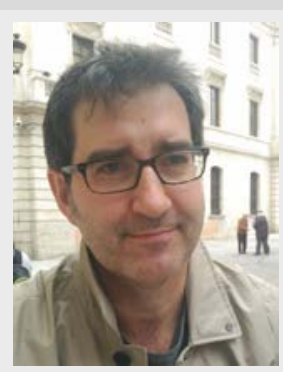
use of Raman-SEC to develop different analytical applications.

Jesus Garoz-Ruiz received his B.S. and Ph.D. in Chemistry from Universidad de Burgos. Since 2017, he is working as postdoctoral researcher. He has developed different devices based on optical fibers coupled to optically transparent electrodes made of nanomaterials and to screen-printed electrodes. His research is mainly focused on the use of the novel devices to study biomolecules and to demonstrate the advantages of SEC, particularly in the field of quantitative analysis.
From a quantitative point of view, the most used SEC techniques are UV/Vis absorption SEC [40-44], fluorescence SEC [45-48] and Raman SEC [49-52]. For this reason, and taking into account the objectives of this review, these three techniques are those that will be described in more detail below.

SEC joins the best of electrochemistry and spectroscopy together [26] during an electron-transfer process. As can be inferred, this multiresponse and "teamwork" technique has been used in a large number of fields, including, for example, electron transfer processes [1,2,53-56], chemical reaction mechanisms [57-62], side reactions [63,64], electrocatalysis [30,31,34,56,57], corrosion [56], conducting polymers [65-70], solar cells [71-75], memory devices [76,77], supercapacitors [7880], synthesis and characterization of nanoparticles [8185], carbon nanomaterials [86-89], characterization of metal complexes [77,90], liquid/liquid interfaces [91-96], electrochromic materials $[97,98]$ or study of compounds of biological interest [40,60,99-106], among others.

The real power of SEC is achieved when it is used in a similar way to electrochemistry, recording the signals continuously throughout the experiment. It is true that electrolyzing a solution to obtain an oxidized or reduced product with respect to the initial reactant can be very useful for extracting information about some compounds or understanding what kind of compound is being produced in an electrochemical experiment [85,107]. However, electrochemistry is an intrinsically dynamic technique, and it is here where the highest potential of this technique is obtained. In a similar way, the dynamic character of SEC is its most powerful feature. Moreover, obtaining time-resolved spectroscopic information is fundamental to understand many electrochemical processes [88,108-111]. In this way, the improvement of the time scale and the sensitivity of the spectroscopic technique are the key factors for the different SEC techniques. In this sense, according to the Lambert-Beer law, the UV/Vis absorption signal is strongly dependent on the molar absorption coefficients of reactants and products, $(\mathrm{A}=\varepsilon \mathrm{lC})$, with different strategies having been developed to improve the absorptometric signal. Raman is a technique with low sensitivity $[112,113]$ but it can be largely improved using surface enhanced Raman scattering (SERS) substrates [114-117]. Finally, fluorescence is a really sensitive and selective technique $[5,118,119]$ making it easy to work at a suitable timescale.

Thus, SEC techniques are not universal and they can only be used to study particular problems. What is certain 
is that, when SEC is used instead of just electrochemistry, much more analytical information can be extracted about the electrochemical processes thanks to interaction of the electromagnetic radiation with the sample.

For many years, SEC has been performed in a thinlayer configuration [13,20,120-125]. Because thin layer techniques are so easy to interpret, they were widely adopted by inorganic chemists to obtain redox and spectra of inorganic compounds and redox proteins such as cytochromes using the electrode developed by Heineman [120]. This strong interest long ago is the reason why the thin layer electrochemical cell using gold grid optically transparent electrodes (OTE) was the first spectroelectrochemistry cell to be commercialized. However, working under semi-infinite diffusion conditions is much more common in electrochemistry. Therefore, SEC under semi-infinite diffusion conditions should be also more useful to understand the usual electrochemical processes. Nevertheless, thin-layer conditions are very interesting for some specific studies.

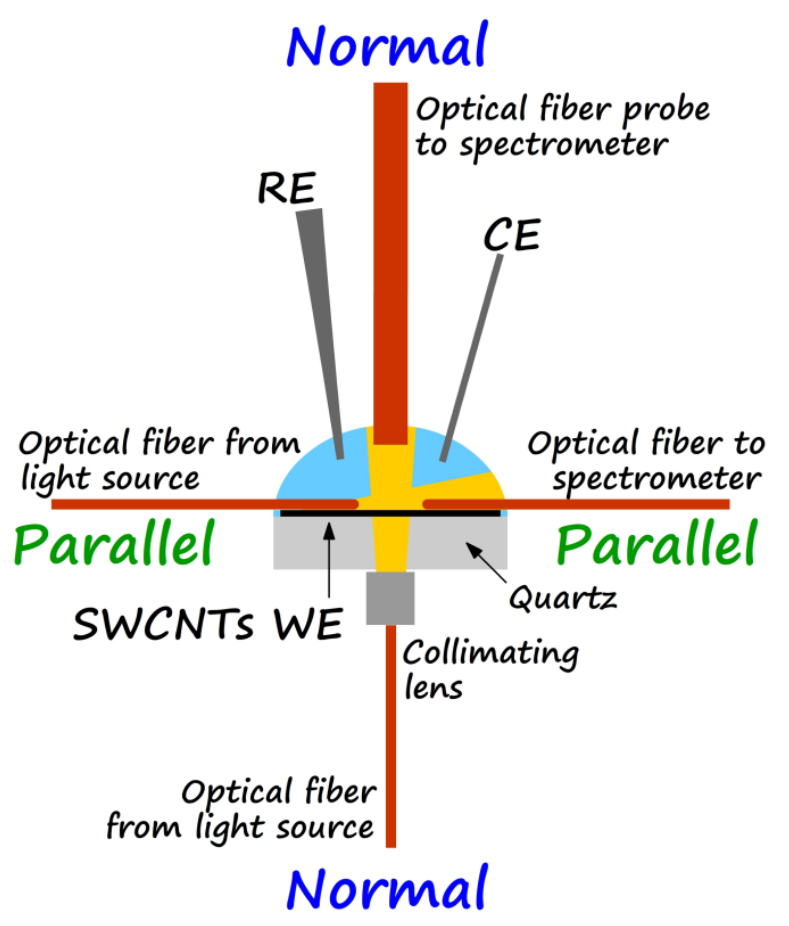

Fig. 2. Schematic view of an experimental setup for UV/VisSEC measurements in both normal and parallel configuration. Reprinted with permission from Ref. [126]. Copyright 2015 American Chemical Society.

\section{How}

\subsection{UV/Vis absorption spectroelectrochemistry}

UV/Vis absorption spectroelectrochemistry combines UV/Vis absorption spectroscopy concomitantly with an electrochemical technique. As non-faradaic currents do not affect the spectroscopic signal, pulse voltammetries are not widely used; however, it could be very useful for quantitative analysis when a double optical/electrical determination is required. Besides, the optical configuration should be appropriately selected depending on the problem to be studied. With this regard, there are two typical optical arrangements in UV/Vis-SEC, namely, normal and parallel configuration, according to the different ways in which the light beam samples the system (see Fig. 2).

Since UV/Vis-SEC was proposed by Kuwana in 1964 [127], a great effort has been done to improve the optical responses. Different strategies have been developed improving the SEC setups. Normal transmission configuration was initially proposed with OTEs. In this case, a perpendicular light beam to the electrode samples both the diffusion layer and the electrode surface $[128,129]$. In order to improve the sensitivity and to avoid the need to use OTEs, the external reflection mode was proposed [130]. In a near normal reflection mode $[131,132]$, the diffusion layer is sampled twice by the light beam, which involves an increase in the sensitivity. As in the previous case, information about the solution and the electrode surface is obtained. In a glancing incidence-external reflection mode [130], the sensitivity is multiplied by more than two since the collected beam forms an angle with respect to the incident beam. Therefore, the sensitivity is slightly higher. Finally, attenuated total reflection mode [133-135] is another interesting approach in which the light beam interrogates the solution from the external face of the electrode. Therefore, as in the normal transmission mode, the electrode material is also limited.

With the aim of improving the sensitivity for soluble compounds, the parallel configuration was proposed [136-138]. In this case, the light beam only samples the diffusion layer parallel and adjacent to the electrode surface, and no information about the surface is obtained.

In 2001, our group proposed a combination of the two typical arrangements, performing a single SEC experiment simultaneously in the two configurations, normal and parallel. The technique was denoted as bidimensional SEC [128]. In this way, information about electrochemical processes taking place on the electrode surface and in the diffusion layer are deconvolved 
because normal configuration provides information about the surface and the adjacent solution while, at the same time, parallel configuration provides information only about the diffusion layer solution. Therefore, bidimensional SEC yields a complete picture about the electrode process and helps to distinguish, without any controversy, if the electrode process is a simple electrontransfer or if there are other processes taking place and accompanying this electron-transfer, as could be for example, an adsorption of the reaction products on the electrode surface [58,64,67,128,139].

Some years ago, SEC was very limited because most of the compounds were studied just in the visible region of the spectrum due to the difficulty of working in the UV region. Nowadays, experimental setups, including light sources, detectors and SEC cells, allow us to work easily in the whole UV/Vis spectrum. Thus, there is a wide variety of compounds that can be studied by UV/VisSEC. Moreover, it is quite difficult, or maybe impossible, to find two compounds that exhibit the same spectra and that are oxidized or reduced exactly at the same potential. Therefore, UV/Vis-SEC is an extraordinary technique to resolve complex samples without any previous separation of the analytes.

\subsubsection{Normal configuration}

Initially, SEC was proposed to be used with OTEs, carrying out normal transmission arrangement because their materials must be not only highly conductive but also highly transparent. Indium tin oxide (ITO) has been one of the most used materials [53] as OTE, but, as it can be reduced, this material can only be used in a relatively small range of potentials. In addition, ITO films fail under bending and there is a limited availability of indium sources [140]. Metallic meshes of platinum or gold, among others, were an alternative very useful for the characterization of compounds [121,141], but this type of electrodes cannot be easily cleaned and the diffusion of compounds around the mesh is not simple. Few pure electrochemistry studies can be found in literature using a metallic mesh as electrode, being the disk electrode much more popular. Therefore, SEC should be more useful if disk electrodes are used. Thin metal films have also been reported in literature [67,124,128,139]. Particularly, gold sputtered films provide a good conductivity and enough transparency together with a reasonably large potential window. Unfortunately, other noble metals such as platinum need a thick layer of material to obtain good conductivities with the consequent decrease in transparency. Carbon nanomaterials constitute a good alternative to ITO, metallic meshes and sputtered films. In fact, the advantages of carbon based OTEs, such as the wide working potential window, the good electrochemical activity, the chemical stability under different $\mathrm{pH}$ conditions and the simplicity of surface modification, are already known for SEC [25,134]. Furthermore, the applications of carbon nanomaterials in analytical chemistry grow significantly [142,143], particularly in electrochemistry [143-145]. Carbon nanotubes and graphene exhibit very good electrical and optical properties, with a high conductivity and transparency and with a wider potential window than ITO electrodes [126,146-148].

In normal transmission configuration, SEC users must be aware of the support of the conductive film. Obviously, a transparent material to UV light has to be used to work in this spectral region, with quartz being the most common material for this purpose. If glass or plastics are used to support the conductive film, only visible SEC can be performed.

Near-normal reflection configuration is an alternative that avoids the use of OTEs. In this arrangement, the light beam is reflected on the electrode surface [131,149], as is shown in the scheme of Fig. 3

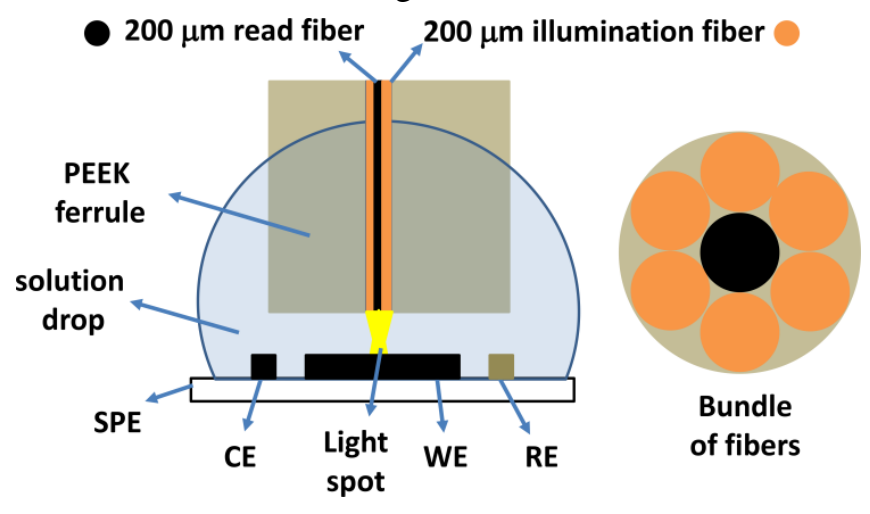

Fig. 3. Schematic view of an experimental setup for UV/VisSEC measurements in near-normal reflection mode. Adapted with permission from Ref. [149]. Copyright 2012 American Chemical Society.

This configuration was not very popular at the initial stages of SEC because it was not very easy to reflect a light beam on the electrode surface. However, by using reflection probes based on optical fibers $[83,131,132]$ and modular spectrometers, the optical setups of these experiments became much simpler than some years before. In this configuration, almost any material can be used as working electrode. Gold [150,151], platinum [83,132], mercury [131] and antimonium tin oxide [152] have been used as electrode material in a similar way to electrochemistry experiments. Carbon can also be used as 
working electrode [149]. Although its reflectance is not remarkable, very good results in UV/Vis-SEC experiments can be obtained [149]. It is noteworthy that, in the last years, screen-printed electrodes (SPE) have been commonly used for SEC experiments [43,149,152,153], being disposable electrodes that can be very useful for analytical purposes.

For SEC measurements in this configuration, users must be sure that the electrode surface does not absorb electromagnetic radiation in the studied spectral region during the whole electrochemical experiment. In addition, the electrode surface should not be deeply transformed because changes of reflectivity can yield anomalous results. Processes where soluble products are generated or very thin films are formed on the electrode surface can be easily studied with this configuration, taking care of the changes in reflectivity, particularly in the case of thin films, due to the real part of the refractive index.
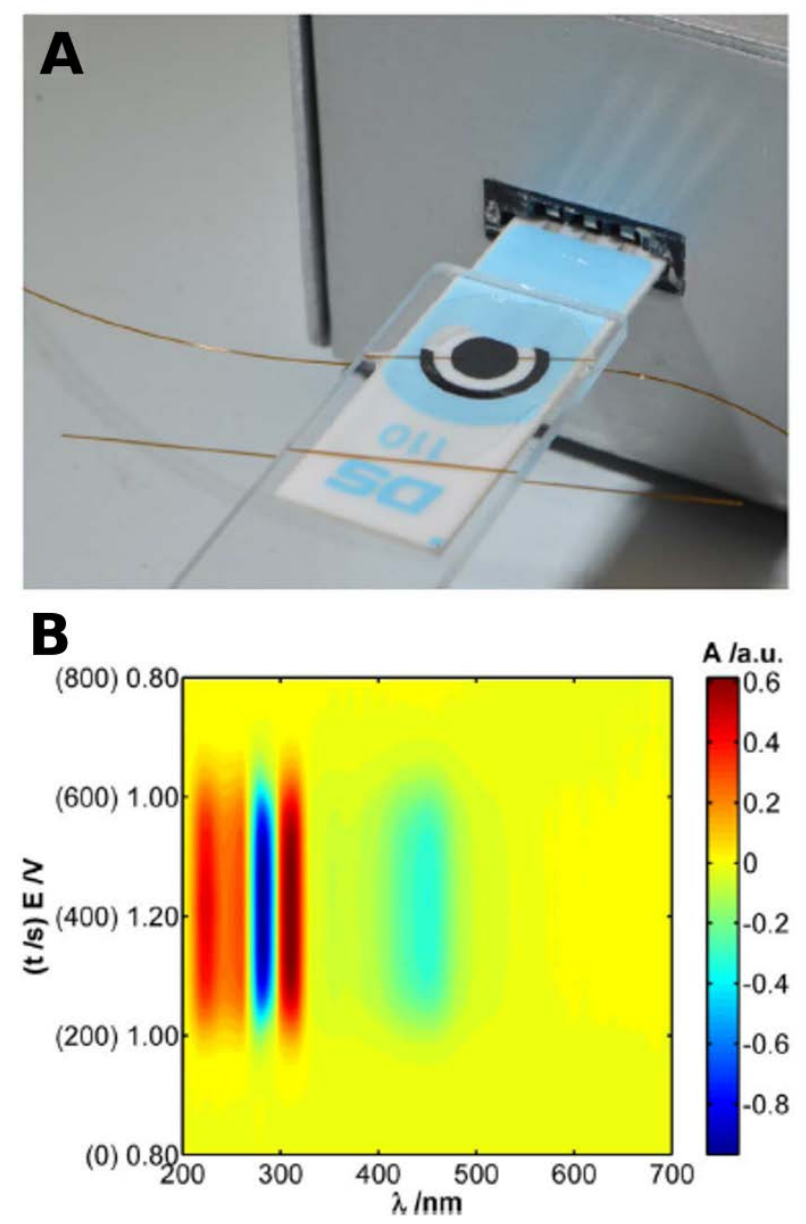

Fig. 4. (a) Photograph of a UV-Vis absorption thin-layer SEC device based on a commercial carbon SPE. (b) Spectra evolution with time/potential recorded during a cyclic voltammetry of $510^{-4} \mathrm{M}\left[\mathrm{Ru}(\mathrm{bpy})_{3}\right]^{2+}$ in $0.2 \mathrm{M} \mathrm{KCl}$ between $+0.80 \mathrm{~V}$ and $+1.20 \mathrm{~V}$ at $0.001 \mathrm{~V} \cdot \mathrm{s}^{-1}$, using the device based on a SPE. Reprinted from Ref. [154]. Copyright 2018, with permission from Elsevier.

\subsubsection{Parallel configuration}

This arrangement is related to the so-called longoptical-path cells. In this case, the optical path coincides with the electrode length or with the distance between the optical fibers, if used. Therefore, the sensitivity for soluble compounds is greatly improved with respect to the normal transmission configuration because the optical path length is commonly larger than the diffusion layer. This configuration was quite difficult to be implemented because the optical alignment was not easy and sometimes the diffusion space had to be limited by suitable spacers in order to improve the sensitivity. This last option, so-called thin-layer configuration, implies a lot of technical difficulties, with the ohmic drop being a challenge to obtain good results.

Nevertheless, there are a number of works in literature very useful to perform this kind of measurements $[102,121,138,153,155]$. However, these setups are not always easy to be implemented by non-experts. If the light beam is thicker than the diffusion layer, there is a deep decrease in the sensitivity because the light beam is not attenuated at far distances from the electrode surface. Therefore, a light beam close to the dimension of the diffusion layer, and passing through the solution adjacent to the electrode surface, is compulsory. For this reason, the thin-layer regime was typically used for the development of these cells, as mentioned before. It should be highlighted that, although the generation of a thin and parallel beam is not easy, measurements in longoptical-path configuration became much easier with the use of optical fibers [156,157], which should absolutely help users to perform parallel arrangement SEC experiments, Fig 4. Finally, it should be noted the good performance of this configuration to obtain information in the UV region, particularly using optical fibers $[126,153]$, due to the high amount of collected light in this spectral region.

\subsubsection{Attenuated total reflection configuration}

In an attenuated total reflection (ATR) configuration [158-160], the light beam, at an appropriate angle, is coupled to and propagates within the OTE by internal reflection, Fig. 5. Attenuation of the light in the ATR configuration occurs within a wavelength or so adjacent to the OTE electrode surface through interaction between the evanescent field of the totally reflected light and light-absorbing species present in this region. Another interesting approach based on optical fibers to perform SEC experiments consists of a core-exposed fiber-optic coated with ITO by a polygonal barrel-sputtering method 
[161]. In this case, sensing is based on changes in an ATR signal accompanying the electrochemical oxidation-reduction of an analyte at the electrode. This sensor is cheap and its mass production could be simple

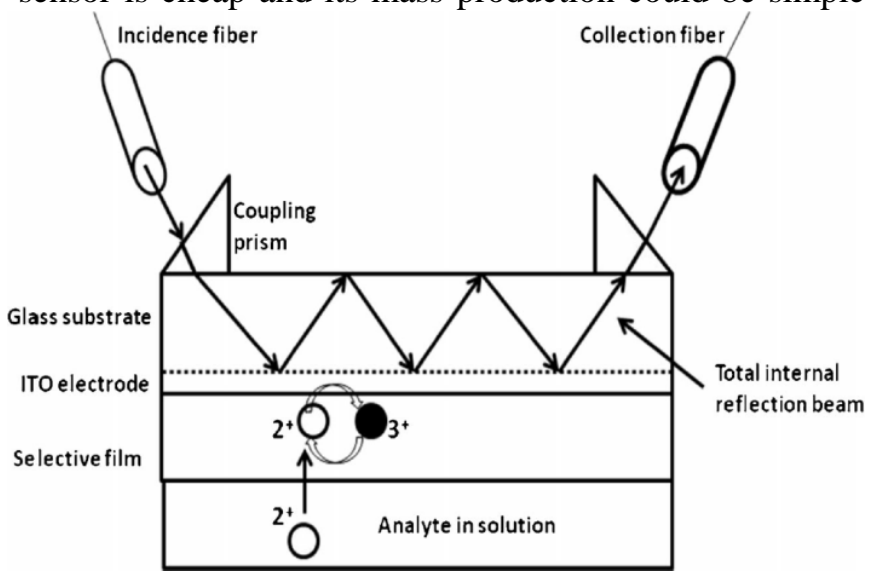

for disposable probes.

Fig. 5. Cross-sectional view of the spectroelectrochemical sensor in the detection of a dicationic analyte such as $\left[\mathrm{Ru}(\mathrm{bpy})_{3}\right]^{2+}$ as it partitions into a negatively charged SSEBS film, is electrolyzed at the ITO electrode and detected by total internal reflection. Reprinted with permission from Ref. [159] Copyright 2012 Wiley-VCH Verlag GmbH\&Co. KGaA, Weinheim

A similar approach, denoted as electroactive fiber optic chip [162], consists of a side-polished fiber optic that is coated with a thin film of ITO as working electrode and is used to probe electrochemically-driven changes in absorbance for surface-confined redox species. A sensitivity 40 times higher than a normal transmission measurement was reported [162].

\subsection{Photoluminescence spectroelectrochemistry}

Fluorescence is one of the most sensitive techniques in analysis [163] and its combination with electrochemistry increases and improves significantly its applications in different fields, particularly with sensing purposes [164]. The main drawbacks of photoluminescence SEC (PLSEC) are the limited number of compounds that yield a good fluorescence and the high interference of ambient light. Also, the experimental setup in PL-SEC is not as simple as the one used in UV/Vis-SEC since the fluorescence intensity is proportional to both the amount of the radiation from the excitation source that is absorbed and the quantum yield of fluorescence [163]. For analytical purposes, a very good optical alignment is required to improve the sensitivity. Additionally, analyte transformation takes place on the electrode surface or in the diffusion layer, as usual. In summary, the experimental setup for fluorescence requires an incident light beam focused on the electrode surface and the collected light beam must be also focused at the same position [5]. Fluorescence microscopy coupled with electrochemistry has demonstrated to be an appropriate way to achieve this instrumental goal. One drawback in PL-SEC is the interference of fluorescent molecules placed in the bulk solution, outside the diffusion layer. To avoid this interference three main strategies have been used to obtain reliable results:

- $\quad$ Classic epifluorescence microscopy using a thinlayer cell [165]. In this configuration, the diffusion space is limited using suitable spacers. Therefore, most of the reactant is transformed, allowing us to obtain a clean photoluminescence signal but, at the same time, the ohmic drop resistance is common in this type of setups. a)

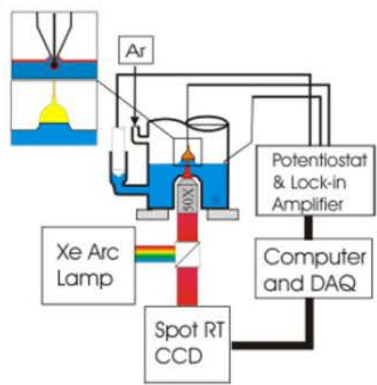

b)

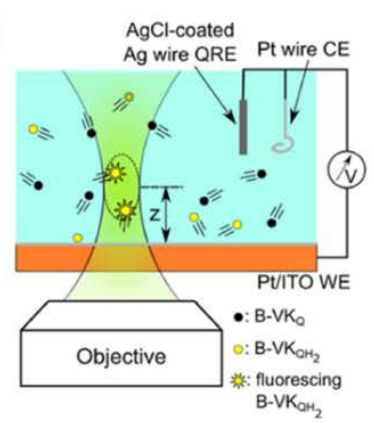

c)

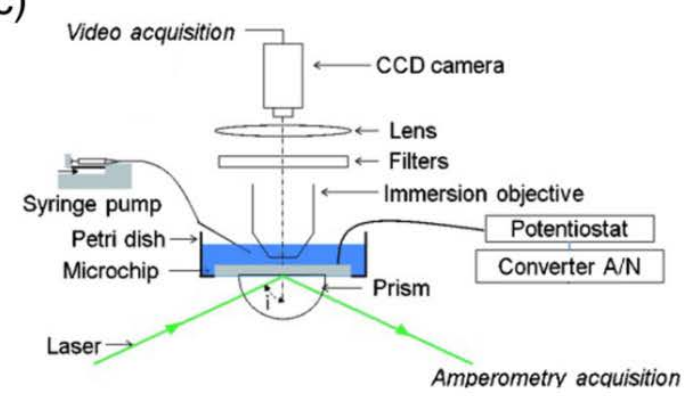

Fig. 6. Schematic depiction of spectroelectrochemical setups for: (a) the inverted epi-fluorescence microscope set-up used to image the electrode surface in either the hanging meniscus arrangement (Au(1 11 1)) or for the HMDE (shown in inset). Reprinted from Ref. [166]. Copyright 2004, with permission from Elsevier.; (b) SEC setup depicting B-VKQ molecules that are oxidized at the surface of the Pt/ITO working electrode and then diffuse through the confocal observation volume (dotted oval) and emit fluorescence. Adapted with permission from Ref. [167]. Copyright 2016, American Chemical Society.; and (C) setup required for TIRF microscopy-amperometry coupling. Adapted with permission from Ref. [171]. Copyright 2011, WILEY - VCH Verlag GmbH \& Co. KGaA, Weinheim. 
Epifluorescence SEC can be also performed under semiinfinite diffusion conditions [166], Fig. 6.a.

- $\quad$ Confocal microscopy $[167,168]$, Fig 6.b. In this case, the microscope includes a spatial pinhole placed at the confocal plane of the lens to remove light coming from outside of the focus plane. In this way, photoluminescence comes only from the focal plane allowing us to obtain the information related to the electrode surface and the diffusion layer.

- Total internal reflection fluorescence (TIRF) [169-171], Fig. 6.c. In this setup, a restricted region of the sample can be observed near the OTE-solution interface. The excitation light interrogates the sample with an incident angle greater than the critical angle determined by refraction laws. Thus, a total reflection of the incident light beam occurs at the OTE-solution interface, and an induced evanescent wave is generated at the interface. The main problem of this configuration is the limitation of electrode materials.

Nevertheless, PL-SEC measurements can be carried out without a perfect focus on the surface, obtaining reliable results that can be used to understand the electrode process [122,172-175]. However, without a good optical alignment, is very difficult to obtain good limits of detection. The development of a simple and reproducible PL-SEC device is still a challenge that must be resolved. It should be noted that light emitting diodes (LED) sources have simplified extremely the experimental setups [46,174-176], using much cheaper instrumentation because both excitation wavelength selectors and lasers can be avoided.

The main advantage of SEC for analysis is the electrochemical transformation of the analytes, or of other compounds that affect the analyte during an experiment, yielding a change in the optical signal during the measurement [45]. Therefore, in PL-SEC is not usual to obtain the excitation spectra and the emission spectra in the same experiment. Neither scanning monochromators nor photomultiplier tubes are commonly used in SEC. If the spectra evolve with time, it does not make much sense to scan the wavelengths during the experiment. A diode array detector is much more useful in this case. SEC measurements could be done at a fixed wavelength, with a photomultiplier tube which improves the sensitivity, but in that case, the powerfulness of SEC to resolve mixtures could be missed. Nevertheless, measurements at a fixed wavelength can be very useful for simple cases where no interferences are expected, as usually happens in fluorescence, improving the sensitivity due to the use of a better detector.

\subsection{Raman spectroelectrochemistry}

Raman spectroscopy is one of the most promising techniques for analysis because a Raman spectrum is a real fingerprint of a compound [112,114]. However, Raman spectroscopy is a technique scarcely used in quantitative analysis due to the weakness of the Raman signal [112]. Since the first time Fleishman et al. [177] reported the unusual intense Raman scattering from the adsorbed pyridine on silver roughened electrodes, SERS has generated more and more interest in the scientific community to amplify the Raman signal, being widely used for analytical purposes [114,117]. However, the increase of sensitivity is usually accompanied by a lack of reproducibility. It should be noted that SERS is a very powerful technique for the detection of few molecules $[178,179]$. However, preparation of good SERS substrates for quantification is still a drawback that must be solved. More and more work is being done in quantitative SERS, but the production of reproducible substrates is complicated and commercial substrates are very expensive.

For a long time, Raman-SEC [27,28] has been performed using powerful Raman spectrometers. Particularly, micro-Raman spectrometers, usually confocal micro-Raman spectrometers, have been widely used $[87,108]$. These instruments provide exceptional Raman signals but they are also very expensive. During the last years, a number of portable low-cost Raman spectrometers have been commercialized and the usefulness of these spectrometers to develop Raman-SEC instruments has been demonstrated in different works $[89,180]$. Micro-Raman spectrometers allow us to obtain very good spatial resolution about the distribution of the sample deposited on substrates [181]. Micro Raman-SEC can be very useful to study the spatial evolution of the electrode surface or the spatial distribution of compounds adsorbed on it, under the effect of an applied potential or current. However, for quantitative purposes, a good timeresolution seems to be more interesting to obtain trilinear analytical information or a deconvolution of the spectral response, provided that the electrode surface is fairly homogeneous. It is true that usually a SERS substrate exhibits zones where the Raman signal is highly amplified. These zones are denoted as hot spots [182]. As can be inferred, a micro-Raman spectrometer allows us to easily find these zones. Hot spots are very interesting to detect few molecules [182], but these regions are still not 
very reproducible and, therefore, it is quite difficult to perform quantitative Raman using hot spots. Moreover, depending on the microscope objective magnification, micro-Raman instruments sample very small areas that, in the presence of nanoparticles (NPs), can be heterogeneous enough to limit the usefulness of RamanSEC in quantitative analysis.

Low-cost Raman spectrometers use Raman probes with a much lower magnification than a micro-Raman spectrometer $[89,180]$, sampling higher electrode areas. Obviously, micro-Raman spectrometers allow us to obtain higher laser energies in the focus and, therefore, a higher Raman scattering but, in some cases, it can be a problem because the sample can be damaged [113].

It should be added that recently a Raman-SEC setup based on the use of a water immersion objective has been developed. In this way, a high detection sensitivity for electrochemical Raman spectroscopy can be achieved [183], which could be very useful for quantitative analysis.

\section{Why}

As is well known, SEC obtains information related to quantitative, thermodynamic, molecular and mechanistic aspects of the system under study $[42,64,126,128,149,184]$, having proven to be really useful to describe the electrode process. A particular SEC technique must be selected depending on the information that we want to obtain about our analyte. As was stated by Royce W. Murray, analytical chemistry is still the science of chemical measurements [185-187]. Thus, analytical chemistry measures important chemical things, which include concentrations, rate constants, and whatever-as long as what is measured is a chemically important parameter [185-187]. From this point of view, SEC is a really powerful analytical technique. SEC can be used with many different purposes, and excellent examples can be found in literature in different fields such as organic molecules [157,188,189], molecules of biological interest [60,120,149,190,191], inorganic complexes [58,192-195], conducting polymers $[65,67,139,196]$, carbon nanotubes $[12,86,88]$, graphene [87,197], fullerenes [12], metal nanoparticles $[81,85,129]$, quantum dots $[175,198-201]$, etc. A huge variety of information can be obtained using SEC, for example, formal potentials [1,2,53,63,202], electron transfer rate constants [203,204], diffusion coefficients [184], number of electrons [1,2,53,63,202,205], molar absorption coefficients [126,202], band-gaps [206], among many others. SEC has also been used in different types of quantitative analysis such as pharmaceutical
[207,208], food [180], clinical [209-211], environmental [211] or industrial [212-214].

In this review, we only discuss the state of the art of SEC when it is used in works related to sensors and associated with their preparation and, in a more meaningful way, with the determination of analytes. Although SEC is not a novel instrumental technique, and in spite of its great potential for analysis, SEC has not yet been widely used for sensing. Years ago, performing a SEC experiment was a difficult task. For example, the optical alignment was a challenge, being very difficult to obtain reproducible results. Nowadays, performing a SEC experiment using, for example, optical fibers is as easy as performing an electrochemical measurement. For instance, in our labs, we use $50-100 \mu \mathrm{L}$ of sample to perform any SEC technique (UV/Vis, PL or Raman), with a time of assembly of the cell being as short as few seconds and obtaining a high reproducibility. All these aspects indicate that a promising future for SEC in quantitative analysis should be expected.

SEC advantages have been described in previous reviews by Dunsch et al. and Mozo et al. [9,12]. These advantages can be commented as follows:

- Direct access to kinetic data of electrode reactions. In this regard, mathematical models similar to the electrochemical ones have to be used.

- Qualitative and quantitative information about the state of the interface at electrochemical conditions. During years, the information extracted from the experiments was mainly qualitative, but, nowadays, obtaining quantitative information about complex mixtures or matrices seems to be one of the most powerful advantages of SEC.

- Efficient set of experimental data at high scan rates. This is one of the main advantages of SEC. When a SEC experiment is performed, a high amount of information about the electrode reaction is obtained. The evolution of the spectra with potential/current along time provides much more information than a simple electrochemical experiment. Usually, a time-resolved SEC experiment consists of hundreds of spectra, each of them containing around a thousand of wavelengths. This fact depends on several factors such as the integration time, the spectrometer, the potential scan rate or the duration of the experiment, but around a million points per experiment are usually obtained. Statistical tools such as multivariate analysis help to extract all the information contained in a set of SEC experiments.

- Fast repetition of experiments at different conditions including a computerized evaluation of data. Although years ago it was very difficult for researchers in SEC to obtain very reproducible data in a short 
time[215,216] (as short as in electrochemistry), now it is very easy to replicate experiments and to assemble the cells. Moreover, the evolution of computers allows us to analyze data as fast as for an electrochemical experiment. Millions of points are easily analyzed. In fact, some manufacturers already provide software properly developed for this purpose.

- Simultaneous acquisition of data from different methods and different nature in a single experiment, which increases the selectivity and sensitivity [217]. Sometimes it is possible to observe chemical reactions taking place at the interface which cannot be observed using the electrochemical signal [58]. Moreover, the high amount of data obtained in a SEC experiment helps to resolve overlapped voltammograms and/or spectra of interfering compounds [43,149]. In addition, spectroscopic signals can be used in different ways, not only as they are obtained, but also using the derivative with respect to time $[44,211,218]$ or with respect to wavelength. Undoubtedly, the high selectivity of SEC is the main advantage of this technique to develop sensors $[43,149,212]$, although, for the time being, few examples of this advantage can be found in literature.

- Separation of the faradaic and non-faradaic contribution of an electrochemical reaction. As is wellknown, the spectral signal is not affected by non-faradaic currents. This advantage has also been scarcely used in literature. Some examples can be found in which the optical signal is much more sensitive than the electrochemical one because of the high capacitive current [132]. Moreover, this interesting property of SEC experiments has almost not been used to study the capacitive currents during the electrochemical process.

Some other advantages should be added to those described in previous reviews [9,12]:

- Development of SEC sensors can be based on the optical response [43,149], but also on both responses (optical and electrical) [42,157]. This last type of sensors provides two independent signals that yield the concentration of the sample with two independent techniques, giving a highest robustness to the analytical method. Moreover, we can consider it as a self-validated method because the method can be performed via the two independent calibrations, without the need of resorting to an external validation method, as suggested by the IUPAC [219].

- Real trilinear data are provided by SEC techniques. When data are indeed trilinear, the true underlying spectra (or whatever constitute the variables) will be found if the right number of components is used and the signal-to-noise ratio is appropriate [220]. Therefore, statistical tools such as parallel factor analysis
(PARAFAC) [220,221], N-way partial least squares (Nway PLS) [222], or multivariate curve resolutionalternating least squares (MCR-ALS) [223-225] are truly useful to solve complex mixtures or to obtain information about unknown contaminants $[41,43,149]$. Furthermore, in PARAFAC, the mathematical model is constructed without providing any information about the chemical system (using only raw data). Therefore, the mathematical model can be constructed without knowing the nature of the interfering compounds [43,149]. Even, although the user did not know if the sample contains an unexpected interfering compound, PARAFAC can predict its presence.

- Small amounts of sample are required. Therefore, few microliters are needed to perform a SEC experiment [126,153] which is an important advantage, not only because obtaining high amounts of sample is sometimes very difficult but also because the lower amount of sample used, the lower amount of waste produced.

- The huge amount of information provided. Information is the basis of the chemical analysis. Few techniques provide as much information as SEC about the electrode process, compounds or materials. In addition, the combination of different SEC techniques yields more powerful instrumentation to analyze an electrochemical process. A good example is the synergy of UV/Vis-SEC and Raman SEC [226]. As mentioned above, the calculation capacity of computers is very high in this century, which simplifies the management of all this information and the subsequent data analysis to evaluate the results.

Additionally, different problems and drawbacks for these in-situ SEC techniques have been proposed $[9,12]$ and can be discussed as follows:

- The low concentration of the electrochemical reaction products at the phase boundary requires a high sensitivity of the in-situ spectroscopic method. With respect to this drawback, it should be noted that SEC is one of the few techniques that study the electrode/solution interface without disturbing the electrode process. It seems clear that better instrumentation and methods are required to improve the sensitivity, but amazing efforts are being done with this objective. For example, the use of shell isolated nanoparticle-enhanced Raman spectroscopy (SHINERS) in Raman SEC [227-229] is a great example of the development of novel methodologies to obtain much better analytical signals at the electrode/solution interface.

- In-situ experiments are time-consuming. This is an old-fashioned drawback. It is true that SEC 
experiments were time-consuming years ago. In our experience, using the new instruments and devices, we can now perform tens of experiments in the time that we carried out just one experiment some years ago. As has been stated above, performing a SEC experiment using one of the new instruments for SEC is as easy as performing an electrochemical measurement. Furthermore, the analysis of SEC data can also be as fast as the analysis of electrochemical data if suitable software is used. Moreover, as often happens, the visualization of the optical response allows us to discard some hypothesis that could be proposed on the basis of only the electrochemical information.

- $\quad$ For the determination of non-electrical properties of the electrochemical system, special cells are required, the type and size of which are adjusted to the requirements of the spectroscopic method which might contradict the requirements of the electrochemical methods in terms of electrode geometry, electrolyte composition, volume, etc. Obviously, the materials for SEC cells should be suitable for the type of selected spectroscopy. However, the development of new cell designs allows us to work with very small samples, as has been stated in the advantages of the technique. Currently, the requirements for spectroscopy are not an impediment to obtain good electrochemical information.

- The selection of solvents, supporting electrolytes and the electrode materials is limited by the requirements of the spectroscopic method. It might be necessary to use materials with less advantageous electrochemical properties, but several new materials and devices have been developed during the last years [230]. Nowadays, it is relatively easy to find proper materials for almost any problem to be studied using SEC, and we hope there will be more developments in the next years to solve the very few existing problems.

- $\quad$ The incident light beam can cause physical and chemical changes inside the spectroelectrochemical cell that are not associated with the pure electrochemical process, producing some variations in the reaction mechanism, the equilibrium constant value or the structure of some species and interfering with the pure electrochemical results. Undoubtedly, the energy of the light beam can interfere in the electrochemical result. However, this interference can sometimes be even produced in an electrochemical experiment by the ambient light, without the researcher being aware and, thus, without taking into account this factor. Modern instrumentation allows us to control the light beam (switch it on/off and control its power) before starting the experiment. Furthermore, the high reproducibility of the measurements allows us to repeat the experiment with or without light to compare the results. Moreover, the optical evolution of the chemical system before starting the experiment can indicate if the system is stable enough. This last information is not available when only electrochemistry is used.

- The applied method might require the addition of such materials to the electrochemical system, which could change the electrode reaction. Again, the selection of materials is fundamental to avoid any kind of interference in the measurement.

- $\quad$ SEC is not a universal technique, like almost any other analytical technique.

- $\quad$ Sensitivity depends strongly on the analyte.

\subsection{UV/Vis absorption spectroelectrochemistry}

As has been stated above, UV/Vis-SEC has been used to measure important things for years, but it has been scarcely used to develop sensors. Most efforts have been done in the development of devices that allow us to obtain good SEC measurements. For this reason, a number of papers employ model molecules to demonstrate the capabilities of the technique. Ferro/ferricyanide [63,231,232], o-tolidine [128,132], ruthenium bipyridine complexes $[147,231]$ or ferrocenemethanol [126,153] are molecules widely studied and used for UV/Vis-SEC. Most advantages of UV/Vis-SEC were proven using these compounds, but the advantages of this technique in quantitative analysis were scarcely demonstrated [213].

As previously mentioned, sensitivity is not the most remarkable feature of UV/Vis-SEC, but in some cases UV/Vis spectroscopy can be as sensitive as electrochemistry, or even better. The right choice of the optical configuration for UV/Vis-SEC measurements is really important to improve the sensitivity. For example, if the product of a reaction is insoluble and is deposited on the electrode surface, normal configuration is much better than parallel one $[67,128]$. On the contrary, when reaction products are soluble and diffuse far away from the electrode surface, parallel configuration is much better than normal UV/Vis-SEC due to its longer optical pathway [126,128].

In our opinion, there are several reasons why UV/VisSEC has not yet been used for the development of sensors:

- $\quad$ Performing a UV/Vis-SEC experiment was timeconsuming a few years ago. Now, the preparation of an experiment is very simple.

- The reproducibility of the UV/Vis-SEC measurements was not as good as of the electrochemical experiments. Nevertheless, some of the 
spectroelectrochemical methods are even more reproducible than strictly electrochemistry such as cyclic voltammetry. For example, the determination of formal potentials and number of electrons by thin layer SEC is very precise. Moreover, for analytical purposes, the novel devices allow us to repeat experiments with low \%RSD and to construct good calibration curves.

- Most of the UV/Vis-SEC experiments were performed using OTEs. Currently, almost any material can be used as working electrode, particularly for the near-normal reflection mode and for the parallel configuration. Moreover, SPEs allow us to use a different electrode for each experiment yielding good and reproducible results.

- In general, UV/Vis-SEC experiments were carried out in steady-state conditions. Now, time-resolved measurements are very simple. The time scale is important for analysis, not only because fast techniques are preferred but also because it is sometimes difficult to reproduce experiments that last a long time.

- $\quad$ Analysis of big datasets was quite difficult with the old computers. Nowadays, computers are real workstations to obtain reliable results in short analysis times.

Therefore, electrochemistry is a fantastic tool to control the composition of a solution. UV/Vis absorption spectroscopy, an analytical technique less sensitive than electrochemistry, is not extraordinary for analysis in itself, but combined with other analytical techniques, it improves their performances. For example, the detection based on UV/Vis absorption spectroscopy is one of the most used for HPLC [233]. In SEC, electrochemistry plays a similar role to the separation of compounds by applying a potential, being possible to detect the changes in the absorbance values. Furthermore, SEC can be used to preconcentrate an analyte on the electrode surface $[44,133,234]$ in order to improve the optical signal. This strategy is a clear example of the synergistic effect of the combination of electrochemical and spectroscopic techniques in one experiment. Preconcentration of sample on the electrode by applying a current or potential can increase the optical sensitivity.

Although the absorbance in UV/Vis absorption spectroscopy is referred to a blank solution without the analyte, the spectrum of the initial solution with the analyte is usually considered as the reference spectrum in SEC experiments [42]. Therefore, changes of absorbance, which are produced when a potential or a current is applied, are usually shown with respect to the initial solution that is taken as reference. Thus, absorbance can take positive or negative values with respect to the initial solution.
Absorption spectra depend on the energy levels of the molecules. Hence, in spite of the possible overlaps, it is almost impossible to find two compounds with identical spectrum. Moreover, even if the spectra are very similar because the absorption band is related to a common chromophore of the two molecules, it is practically impossible that these two molecules have the same electrochemical behavior and are oxidized and/or reduced at the same potential. Therefore, it should be highlighted that, although electrochemistry and UV/Vis absorption spectroscopy are not particularly selective techniques by themselves for analysis, the result of their coupling, known as UV/Vis absorption SEC, is very useful for the resolution of mixtures in a more or less simple way. In some cases, multivariate statistical tools are needed to resolve the mixtures $[41,43,149]$.

Most of these reasons that have limited the development of sensors, and the corresponding solutions to these drawbacks, can be extrapolated to PL-SEC and Raman-SEC.

\subsection{Photoluminescence spectroelectrochemistry}

As is well-known, molecular fluorescence spectroscopy is an analytical technique characterized by a very high sensitivity, usually significantly higher than UV/Vis absorption spectroscopy, because it is relatively easy to distinguish dark background from low levels of light [235]. Additionally, it can have an exceptional selectivity by using specific fluorescent molecular sensors [163]. Therefore, it is not surprising that this technique has been used for the determination of a great variety of compounds, thanks to these advantages. The accuracy and sensitivity of this technique are really high for analytical purposes, but it is also influenced by the quantum yield. For example, detection limits are strongly influenced by the quantum yield of the analyte or the molecule used to its indirect determination, but molecules with a high quantum yield exhibit detection limits in the range of ppb or even ppt. Most of the advantages and drawbacks of UV/Vis-SEC can also be extended to PLSEC. Sensitivity and selectivity of PL-SEC can be even better than UV/Vis-SEC because, in general, changes in emission intensity are usually higher than absorbance changes. Photoluminescence can better discriminate dark background from low levels of light emitted. In general, there is a difference in either excitation or emission spectra of analyte and interfering compounds. In addition, the length of the optical pathway is not so important in fluorescence as in absorption techniques [235].

Electrochemistry, as has been stated above, can provoke changes in fluorescence in different ways. It is 
possible to generate or consume a fluorescent compound by an electrochemical reaction occurring at the electrode surface, while changes in the light intensity are simultaneously measured. Thus, the oxidation/reduction of the reactant leads to changes of the fluorescence spectra, but additionally the oxidation/reduction of some other compound in solution can enhance or quench the fluorescence. This effect can be used to indirectly quantify or identify this compound [46,59,236,237].

Other alternatives have been proposed to enhance the sensitivity in PL-SEC. By using an array of nanopore ring electrodes fixed on an optically transparent support, bifunctional nanopores with nanophotonic and nanoelectrochemical behavior were obtained [118], Fig 7. Using this analytical strategy and repeating cycles of oxidation and reduction of the analyte, based on the cross-correlation of single molecule fluctuations in electrochemical and photon-emission responses, singlemolecule detection was achieved.

\subsection{Raman spectroelectrochemistry}

As was stated above, Raman spectroscopy provides a fingerprint of molecules [112,238]. From a qualitative point of view, it is one of the best analytical techniques to identify a molecule. Unfortunately, Raman scattering is very weak [112], and therefore this spectroscopy should not be very suitable for quantitative analysis. However, Raman signal can be greatly amplified by using a surface-enhanced Raman scattering (SERS) substrate [112,114,116,117], with Raman spectroscopy being even a single-molecule detection technique $[179,239]$. Since the discovering of SERS effect [177], this phenomenon has taken more interest in the scientific community. It is well known that SERS on metal electrodes occurs due to the combination of two main mechanisms [114,116,117]. The first one is known as electromagnetic mechanism (EM), which implies the amplification of the Raman signal because of the increase of the electric field at the surface of the metal when the incident photon excites the surface plasmon (SP) of the nanostructured or roughened surface $[240,241]$. The second one involves the chemical interaction between the molecule and the nanostructured metal surface in such a way that promotes a charge transfer between them. This phenomenon is known as chemical enhancement mechanism (CM), and provokes an additional increase of the Raman signal [114,116,117].

Resonance Raman can also help to improve the sensitivity of Raman-SEC, particularly, coupled to SERS.

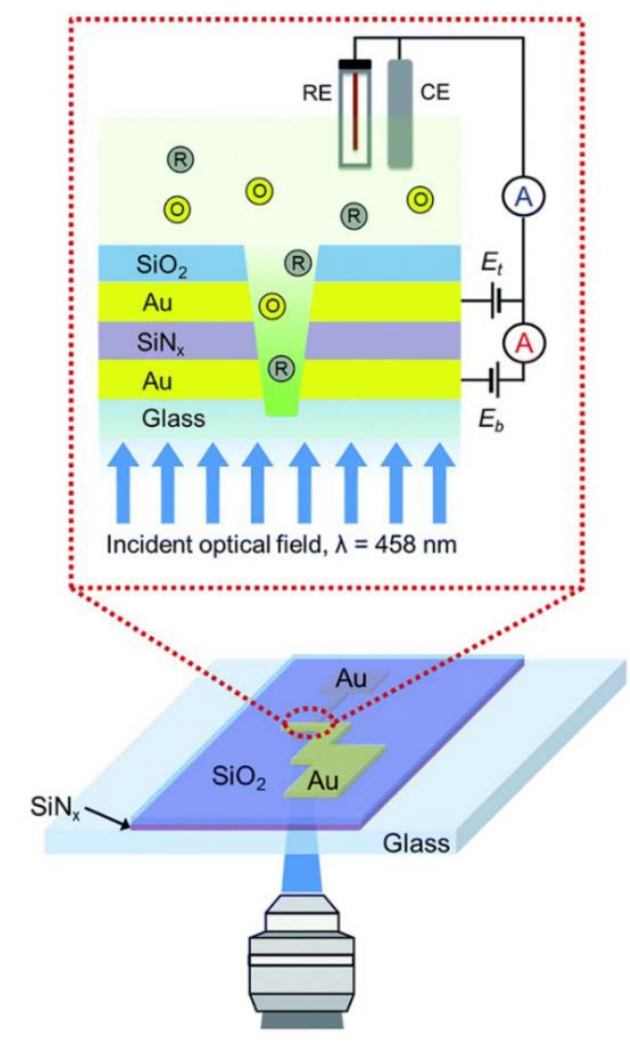

Fig. 7. Electrochemical zero-mode waveguide (E-ZMW) device. Schematic diagram of the experimental configuration. Freely diffusing redox-active molecules are repeatedly reduced and oxidized at recessed dual ring electrodes, leading to a measurable current. As focused light from a $458 \mathrm{~nm}$ laser penetrates into the E-ZMW, its intensity exponentially decreases to generate a zeptoliter-volume excitation volume confined near the bottom electrode. The E-ZMW can be used to observe single electron transfer events using simultaneous optical and electrochemical measurements. Adapted with permission from Ref. [118]. Copyright 2017, The Royal Society of Chemistry.

Thus, a correct selection of the laser energy is compulsory.

The usual materials that present plasmonic properties at the nanoscale are silver, gold and copper. Therefore, these metals can be used as electrodes for the detection of different molecules in Raman-SEC [49-51,242].

The high selectivity of the technique together with the high sensitivity of SERS substrates make Raman-SEC one of the most promising techniques for quantitative analysis. Additionally, electrochemistry can be used either to prepare SERS substrates $[49,50]$ or to adsorb the analyte on the surface of the plasmonic structures in order to improve the analytical signal $[15,51]$.

From the bands observed in the Raman spectra, Raman-SEC also provides information about the orientation of the molecules on the electrode as a function 
of the potential [243] and about the modification or the transformation of the electrode surface [244,245].

Most of the advantages and drawbacks of UV/Vis-SEC can be also applied to Raman-SEC. Therefore, the huge amount of information, the trilinearity of the technique, the simple preparation of the experimental setups, the capacity of electrochemistry to provoke changes in the characteristic Raman spectra, the use of SPE and the improvement in the reproducibility of the experiments are reasons to expect an important development of RamanSEC in quantitative analysis.

\section{Advantages in use}

In this section we will illustrate the capabilities of the different SEC techniques in quantitative analysis. The examples have been selected to show the advantages that can be obtained by using SEC.

\subsection{UV/Vis absorption Spectroelectrochemistry}

UV/Vis-SEC was born more than fifty years ago. Since then, this technique has not yet been established as a usual technique for analysis. During the first years of the technique, most efforts were focused on the development of new UV/Vis-SEC devices. Cells for normal configuration both in transmission [9,121] and reflection $[9,130]$ mode were developed together with novel cells in parallel configuration $[9,137]$ with a much longer optical path, allowing a considerable improvement on the sensitivity of the technique. UV/Vis-SEC was preferentially used for studying chemical compounds of different nature $[65,83,246]$, demonstrating the utility and versatility of the technique in different research fields. During the initial stages of the technique, few examples of quantitative analysis can be found [137,158,208,247250], with a much higher number of works that use UV/Vis-SEC for studying reaction mechanisms and for assessing typical electrochemical parameters such as the number of electrons involved in the electrode process [63,153], formal potentials [63], electron-transfer rate constants [203,204] and diffusion coefficients [184].

The improvement of the experimental setups [42,126,149,157] was a trigger for quantitative applications. Thus, most of the analytical applications were developed at the end of the $20^{\text {th }}$ and the beginning of the $21^{\text {st }}$ century. UV/Vis-SEC was used to determine compounds as acetaminophen or chloramphenicol in long optical pathway cells [208,251], but, in general, both the limit of detection and the experimental time were far from the values achieved by the electrochemical techniques. Acetaminophen was determined twenty years later in tablets that contained a clear interfering compound, achieving a good deconvolution of the optical signal by using matrix-augmentation multivariate curve resolution-alternating least-squares [41]. This work is quite interesting because it demonstrates that thanks to the trilinearity of the UV/Vis-SEC signal, an analyte can be determined in presence of an unknown interfering species. The Achilles heel of this work is that a mesh OTE is used, with not very good sensitivity and a complicated to use cell. The capability of UV/Vis-SEC to resolve complex mixtures using multivariate statistical tools was also demonstrated using a device based on optical fibers [43]. In this work, catechol clearly interferes the electrochemical and optical signals obtained for dopamine, Fig. 8a, making it impossible to obtain reliable univariate calibrations of dopamine when catechol is added in variable concentrations. Analysis of the optical signal using parallel factor analysis (PARAFAC) not only makes possible to determine dopamine, but also the amount of catechol in the samples, Fig. 8. The same idea has been demonstrated with other mixtures such as dopamine/epinephrine [43]. Undoubtedly, this is the most important advantage of UV/Vis-SEC sensors. For the time being, UV/Vis spectroscopy still cannot compete with electrochemistry with respect to limits of detection, but it is much more powerful to resolve complex mixtures avoiding the typical separation methods. Actually, the electrochemical component of the technique helps to separate the signals of the different analytes and interfering species present in the solution. When analytes are very separated in terms of potential and/or wavelengths, their determination is much easier. In these cases, a simple univariate statistical analysis is required to determine the compounds in solution.

UV/Vis-SEC can also be robust for the determination of compounds in real media. As can be seen in Fig. 9, by using devices based on optical fibers fixed to the working electrode in parallel configuration, it is even possible to work inside a fruit [42]. This setup, composed by a flexible three-electrode system based on carbon nanotubes, was used to determine ascorbic acid inside a grapefruit. The main achievement of this work is to show that UV/Vis-SEC does not need to be performed in a spectrophotometric cuvette or in a complex cell, but in almost any type of sample. In addition, optical fibers in parallel configuration $[43,157]$ also allow us to work with very small volumes, reason why UV/Vis-SEC is already a technique capable of working at the microscale. 

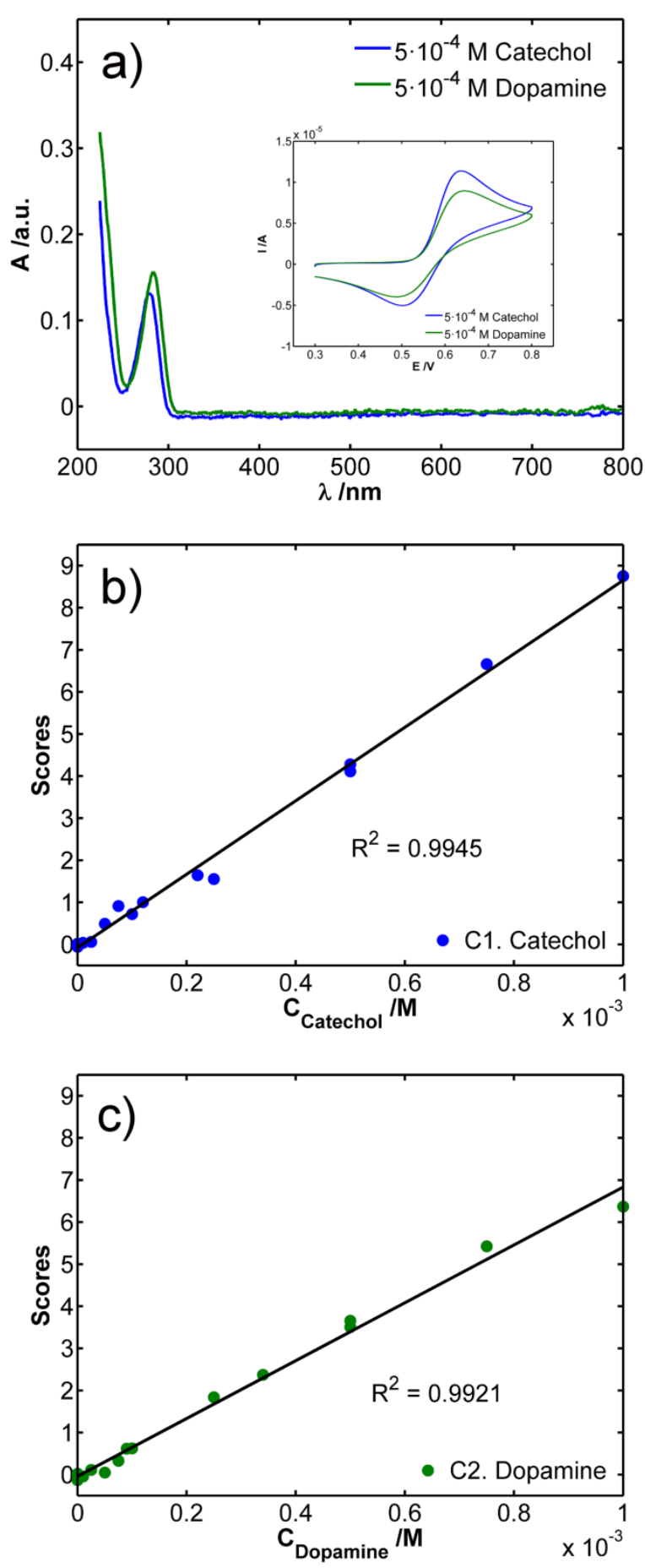

Fig. 8. a) This figure is related to solutions $5 \times 10^{-4} \mathrm{M}$ catechol or $5 \times 10^{-4} \mathrm{M}$ dopamine in $1 \mathrm{M} \mathrm{HCl}$. Initial spectra (taking a $1 \mathrm{M} \mathrm{HCl}$ solution as reference spectrum). Inset: Cyclic voltammograms between +0.30 and $+0.80 \mathrm{~V}$ at $0.01 \mathrm{~V} \mathrm{~s}^{-1}$. Representation of the linear behaviour of the raw scores obtained with PARAFAC with respect to the concentration of (b) catechol and (c) dopamine. Reprinted from Ref. [43]. Copyright 2019, with permission from Elsevier.
This feature is important because in some cases it is quite difficult to obtain large amounts of sample, not only for chemical analysis but also for the characterization of compounds that are not easily obtained. For example, when optical fibers in parallel configuration are used in a thin-layer setup [153], volumes as small as $20 \mu \mathrm{L}$ can be used.

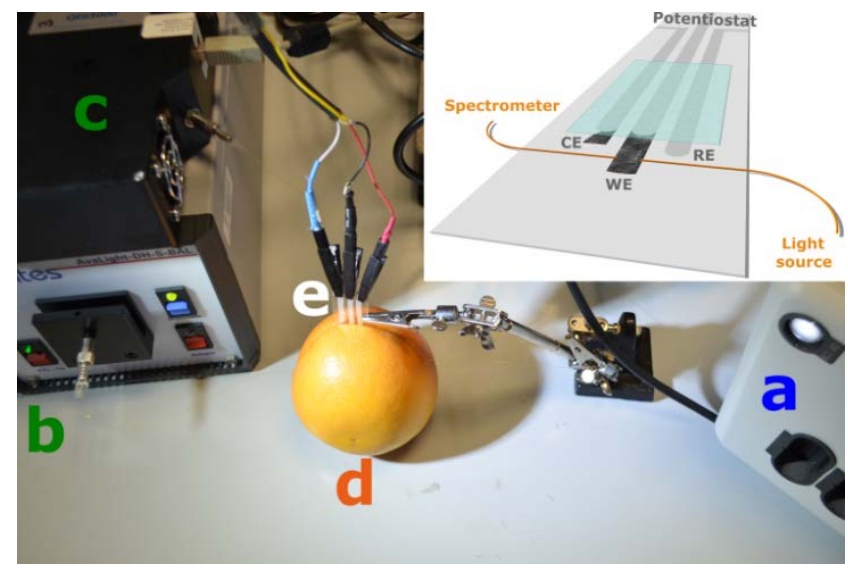

Fig. 9 Device placed inside the grapefruit to perform a spectroelectrochemistry measurement. Setup only requires the (a) potentiostat, (b) light source, (c) spectrometer, (d) grapefruit, and (e) spectroelectrochemistry device. Inset: Illustration of the spectroelectrochemistry device. Adapted with permission from Ref. [42]. Copyright 2017 American Chemical Society.

It should be highlighted the combination of UV/VisSEC with SPEs because it allows us to avoid problems of fouling of the working electrode. For example, during the oxidation of dopamine at $\mathrm{pH}=7$, an insoluble product is formed on the electrode surface. Polishing the electrode surface can affect dramatically its reflectivity and, depending on the researcher, the results may not be reproducible enough. Moreover, the previous experience in polishing electrode surfaces is fundamental, so a nonexpert user might not be able to obtain good results. However, using a brand new SPE for each experiment, high reproducible results can be obtained in short times [149].

UV/Vis-SEC sensors are also very robust because a double information on the same system is obtained. Therefore, two different calibration curves can be performed at the same time, one electrochemical and one optical. Therefore, the user can realize that, if a significant difference in the concentration is found between the two techniques, the results, or at least one of them, might not be true. This is very important to avoid undesirable and incorrect results. Therefore, one of the 
signals can validate the other one. This feature has been demonstrated in the determination of heavy metals by UV/Vis reflection SEC [234] and in the determination of dopamine and catechol [149,157].

Playing with reactants, solvents and potentials, the sensing performance of a SEC analytical method in terms of sensitivity and selectivity can be highly enhanced compared to optical sensors. For example, the electrochemical reduction of Meisenheimer complex in a deep eutectic solvent modified with $n$-butylamine has been used for a superselective UV/Vis-SEC determination of 2,4,6-trinitrotoluene [252], improving the selectivity by a factor of $10^{3}-10^{4}$ with respect to an optical sensor.

ATR has been widely used to determine different analytes [212,214,253-256], and the combination with sensing films is an interesting strategy for analytical purposes. For example, a SEC sensor can be developed for a metal ion that lacks the optical properties needed for this type of sensors by forming a strongly absorbing metal complex within a sensing film. This methodology was demonstrated for the determination of aqueous iron by in-situ complexation with 2,2'-bipyridine [257], using an ITO electrode coated with a thin film of Nafion.

In other works, a mediator can be used for SEC sensing, as was demonstrated in the determination of both ascorbic acid and ascorbate using Ru(bipy) ${ }_{3}{ }^{2+}$ as a mediator [255]. This concept could be extended to biosensors.

Another approach found in literature uses an ITO that has been overcoated with a sol-gel-derived chargeselective thin film, demonstrating the usefulness of this methodology, as a proof of concept, in the determination of ferrocyanide [158].

Electrochemistry can be used to accelerate reactions and this strategy has been used to determine melamine in a real sample by using SEC [258]. Also, electrochemistry can be used for an electrochemically assisted solvent extraction method. This strategy was used as a colorimetric sensor for lead determination [259].

In the same way as in electrochemistry, the analyte can be preconcentrated using stripping analysis. This methodology has been successfully used for the determination of different heavy metals [133,234,248,250,258,260,261].

Depending on the analytical strategy, SEC is a very useful technique for multianalyte determinations in a single experiment. Heineman et al. combine an optical stripping voltammetry to determine $\mathrm{Pb}(\mathrm{II})$ and the in-situ ligand complexation in a film to detect Fe(II) [262].

The indirect monitoring of hydrogen-phosphate ion based on the electrochromism of a spinel-type oxide thin- film is an interesting approach to quantify non-absorbent compounds [258]. UV/Vis-SEC indirect methods have been also used to determine cysteine [259] and NO [263].

Kuramitz et al. [264] use a SEC sensor that consists of a gold mesh cover on a multimode optical fiber that uses attenuated total reflection as the optical detection mode for the simultaneous determination of methylene blue and ferrocyanide as model analytes. In this work, sensor responses were improved with an additional level of selectivity via an electrostatically adsorbed, selfassembled monolayer which consisted of a silane coupling layer, a polyanion and a polycation.

Electroactive integrated optical waveguide has been shown to be a powerful device for the SEC characterization of submonolayers of adsorbed materials [265].

In some cases, UV/Vis-SEC is interesting to find outliers. Optical signal can provide information that reveals whether an unexpected process is taking place on the electrode surface [149]. This interference usually cannot be detected from the electrical signal which simply changes, but the user cannot know that this change is related to an unexpected process. However, when the system is "observed" by the optical signal, the user can easily detect the presence of an unexpected interfering process.

SEC flow cells can be used to transport the sample to the electrode in a continuous way. Thus, two main advantages are obtained: a very high reproducibility and a high efficiency in the rate of mass transport. Some nice examples can be found in literature that were applied to the determination of iron compounds [266], cadmium [234], chlorpromazine [267] and promethazine [207], among others [124,247,249,261,268].

RGB cameras can be used to perform quantitative UV/Vis-SEC. Color video images are composed by a matrix of the three components RGB that provide spectral information about compounds in solution or deposited on the electrode. Paengnakorn et al. [269] used this approach to resolve Fe(II/III) mixtures using a simple webcam.

A scarcely used approach in chemical analysis consists of using localized surface plasmon resonance (LSPR) sensing. This method relies on localized field enhancement and confinement in close proximity to NPs and therefore requires very limited space for sensing. Particularly, it has been used for determination of neurotransmitters [270].

UV/Vis-SEC can also be very useful in the preparation of sensors. During the last years nanomaterials are being widely used to determine a number of molecules $[82,190]$. For example, electrodeposition of NPs is a 
well-stablished method to prepare sensors. The electrodeposition process can be properly followed by UV/Vis-SEC [82,83], providing information that could only be obtained using an $e x$-situ technique such as for example SEM. The confirmation of the generation of NPs on the electrode surface, in a direct way and in a shorter time, can help to be sure that the modification of the electrode has been successfully performed. UV/Vis-SEC cannot provide the exact size of the NPs, but it provides information on the shape [271] and, which is more important, on the reproducibility of the electrodeposition process. Moreover, an ex-situ characterization of the electrode surface does not guarantee that the modification employed for the determination is identical to the used for the SEM characterization because the electrodeposition process might not be reproducible and the NPs can evolve with time even without contact with a solution.

Finally, in a recent work, UV/Vis-SEC has been proposed to compare simultaneously the modified and unmodified regions of an electrode surface under exactly the same experimental conditions [272] in order to confirm, in a single experiment, that the modified electrode exhibits the expected properties with respect to the original one.

\subsection{Photoluminiscence spectroelectrochemistry}

Fluorescence is sometimes too specific. An interesting methodology to determine non-fluorescent compounds consists of using an indirect via, for example, combining PL with electrochemical reactions. Heineman et al. [47] used a TIRF setup to carry out the indirect determination of 1-hydroxypyrene from an acidic sample by fluorescence of electrochemically generated dihydroxypyrene at an ITO electrode modified with 20 $\mathrm{nm}$ Nafion film that rapidly preconcentrated the analyte at the sensor surface. This experimental procedure represents an interesting model that can be used for other target molecules.

Martín-Yerga et al. [46] determined chloride by provoking the electrochemical oxidation to $\mathrm{Cl}_{2}$ that reacts with a fluorescent molecule, rhodamine $6 \mathrm{G}$, yielding a bleaching of fluorescence, Fig. 10.

An indirect monitoring of the fluorescence of a copper center of a nitrite reductase in response to electrode potential and catalytic turnover allows the nitrite detection [236].

PL-SEC can provide sensitivities that are unprecedented for electrochemistry on macroscopic surfaces. The redox states of appropriately tagged surface-immobilized blue copper proteins can be optically sampled down to levels of a few hundred molecules [273].

Generation of luminescent complexes has been demonstrated to be an interesting strategy to improve the sensitivity for detection. A good example is the determination of $\mathrm{Ru}(\mathrm{II})$ with sensitizing ligands such as 2,2'-bipyridine [48], where the resulting complex shows a red luminescence with a high quantum yield of emission that significantly improves the detection limits for $\mathrm{Ru}(\mathrm{II})$.

Detection of lanthanides and isolating signals of these elements, in particular of europium, have been achieved by complexing this element with different sensitizing ligands. SEC is limited by the low molar absorptivities and quantum yields of the lanthanides. These limitations can be circumvented by complexing the lanthanides with sensitizing ligands that enhance fluorescence. Moreover, the emission from the oxidized complexes allows to uniquely identify $\mathrm{Eu}$ [194].

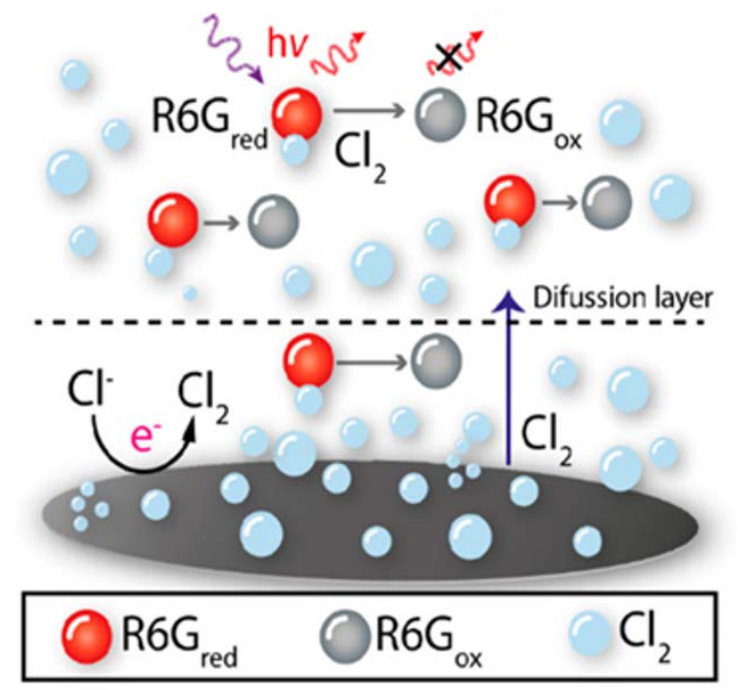

Fig. 10. Illustrative scheme of the bleaching process after the electrogeneration of gaseous $\mathrm{Cl}_{2}$ species. $\mathrm{Cl}_{2}$ bubbles are detached from the electrode surface to the bulk solution where they react with R6G. The initial luminescent reduced R6G (R6Gred) is oxidized to a nonluminescent product (R6Gox). Reprinted with permission from ref. [46]. Copyright 2018, American Chemical Society.

Other metal ions such as $\mathrm{Cu}(\mathrm{II})$ can be challenged by fluorescence quenching of the ligand calcein after cathodic preconcentration of $\mathrm{Cu}(\mathrm{II})$ and subsequent stripping in a solution with this ligand, achieving detection limits in the order of $10 \mathrm{nM}$ [237].

A simple thin-layer cell based on an SPE has been used to determine tris(2,2'-bipyridyl)dichlororuthenium(II) 
complex with a limit of detection of $36 \mathrm{nM}$, demonstrating the high sensitivity of PL-SEC [235].

The thin-layer approach was also used to quantitatively distinguish between 1-hydroxypyrene and 1hydroxypyrene-glucuronide [45]. These polycyclic aromatic hydrocarbon biomarkers exhibit overlapped fluorescence spectra and can be determined using PLSEC without the need of a separation step. These compounds show near identical absorbance and fluorescent spectra and a large difference in their initial oxidation potentials, demonstrating the capability of SEC to separate the optical response of different compounds.

Sometimes, PL-SEC is quite useful because there are few fluorescent compounds. For example, in the case of a $\mathrm{Ru}(\mathrm{bpy})_{3}{ }^{2+} / \mathrm{Fe}(\mathrm{bpy})_{3}{ }^{2+}$ test mixture, the absorbance-based sensor, without using multivariate analysis, failed to distinguish between the analyte and the interfering compounds using only the spectroscopic mode. However, during the modulation of potential in a PL-SEC experiment, the electrolysis of the $\mathrm{Fe}(\mathrm{bpy})_{3}{ }^{2+}$ does not contribute to the emission at $605 \mathrm{~nm}$ and the optical modulations seen for the test mixture are only due to the electrolysis of the $\mathrm{Ru}(\mathrm{bpy})_{3}{ }^{2+}$ [262]. This work is quite interesting because Heineman et al. combine ionic, electrochemical and optical (absorbance or fluorescence) detection. This triple sensor helps to avoid interferences and improve the selectivity of SEC, in particular, PLSEC.

Unwin et al. [274] proposed other interesting application in which by using a fluorescence confocal laser scanning microscope are able to obtain threedimensional $\mathrm{pH}$ profiles as a function of the applied potential to an ultramicroelectrode. They demonstrate that the combination of fluorescence and electrochemistry allows measuring local changes of $\mathrm{pH}$ occurring at the ultramicroelectrode surface, which is highly important in electroanalysis.

\subsection{Raman spectroelectrochemistry}

As has been stated above, Raman spectroscopy is a technique with a very low sensitivity [112]. In order to improve this sensitivity, the preparation of electrode surfaces with SERS properties is mandatory. However, reproducible SERS substrates are difficult to be obtained. In general, electrodes modified with Ag, Au and Cu NPs have been used for analytical purposes. For example, Brosseau et al. have modified electrodes with $\mathrm{Au}$ and $\mathrm{Ag}$ NPs to determine uric acid in synthetic urine [51]. It should be noted that electrochemistry plays a key role in the determination of uric acid because this molecule is electrochemically adsorbed on the modified electrode surface, Fig. 11, improving the analytical signal.

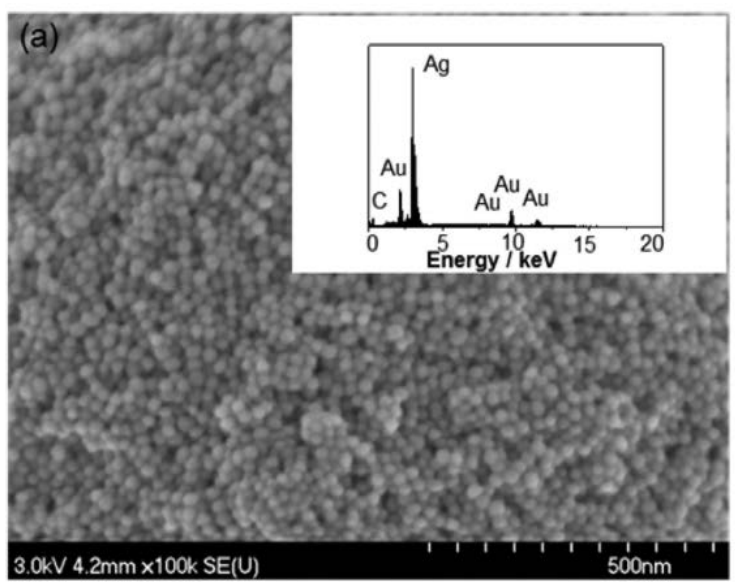

(b)

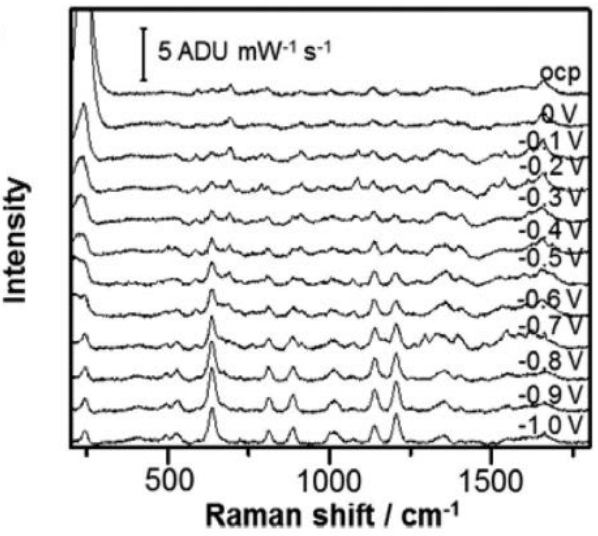

Fig. 11. (a) SEM image of the Au/Ag substrate prepared on a screen printed electrode. Inset: EDS result of the corresponding $\mathrm{Au} / \mathrm{Ag}$ substrate. (b) Electrochemical-SERS spectra for $0.5 \mathrm{mM}$ uric acid in synthetic urine supporting electrolyte. Applied voltage was stepped in the cathodic direction in $100 \mathrm{mV}$ increments. Laser excitation was $532 \mathrm{~nm}$. Power at the sample was $1 \mathrm{~mW}$, and acquisition time was $30 \mathrm{~s}$. Adapted with permission from ref. [51]. Copyright 2015, American Chemical Society.

$\mathrm{Au}$ NPs have also been used for the study of DNA bases, nucleotides, DNA aptamers and microRNA $[275,276]$. Determination of $p$-aminothiophenol was carried out using Ag NPs obtained by green synthetic methods [277].

Nanostructured electrodes have been used to determine cystatin $\mathrm{C}$, which is used as a protein biomarker model useful for the early diagnosis of Alzheimer's disease, in blood plasma down to $1 \mathrm{pM}$ and a low RSD (3.8\%) [210]. In this work, cystatin is determined using both SERS and differential pulse voltammetry. Two different methods were used for the same sample. Moreover, cyclic voltammetry was used to recycle electrochemically 
the extractor chip after use, desorbing the inactive antibody fragments and then producing the refunctionalization with fresh fragments.

One alternative way to prepare SERS substrates is the use of metal roughening to form NPs with plasmon band. This methodology has been used for many years, but it has been scarcely used for quantitative purposes since the fabrication of reproducible substrates is difficult.

During the last years, preparation of SERS substrates by roughening of SPEs has appeared as an interesting alternative to the roughening of classical metal disk electrodes. Combination of in-situ roughening including the target molecule in solution and time-resolved SEC is providing a good reproducibility, obtaining sensitive results in very short experimental times in comparison to classical $e x$-situ methods in which very long procedures were used to obtain SERS substrates. Silver SPEs have been used for the determination of ferricyanide and tris(2,2'-bipyridyl)dichlororuthenium(II) complex in nanomolar concentration [49]. This methodology has also been used for the determination of malachite green which is a mutagenic agent [50] and for the determination of naratriptan, which is an active pharmaceutical ingredient [278]. Moreover, single molecule detection can be achieved by using the simple roughening of a silver SPE [239].

Recently, Colina et al. [154,279] have proposed a new way to enhance the Raman signal using a completely alternative method to classical EC-SERS. In these works, the amplification of the Raman signal is obtained during the oxidation of a silver electrode, and this enhancement is only obtained when an anodic potential is applied to the electrode. For this reason, this method has been denoted as electrochemical-surface oxidation enhanced Raman scattering (EC-SOERS). This phenomenon has been used for a reproducible determination of citric acid, Fig. 12, and a good linear relationship of the Raman signal with uric acid concentration has also been observed [154]. This new methodology seems to be promising for the determination of molecules that are not very sensitive in SERS, such as organic acids.

Recently, Brosseau et al. [280] have performed the ECSERS bacterial detection and identification. The results show that Raman-SEC improves the performance of the SERS substrates and suggests that it is a very promising screening method for bacteria.

Indirect measurements are an interesting strategy that can be used for analysis. For example, EC-SERS can provide in-situ and real-time monitoring of the doping/dedoping conversion of poly(EDOT-OH) and a quantitative measurement of oxidant concentration [52]. Real-time monitorization of the Raman spectra change of
poly(EDOT-OH) at dedoped state can be used for the determination of $\mathrm{H}_{2} \mathrm{O}_{2}$ solutions of different concentrations.
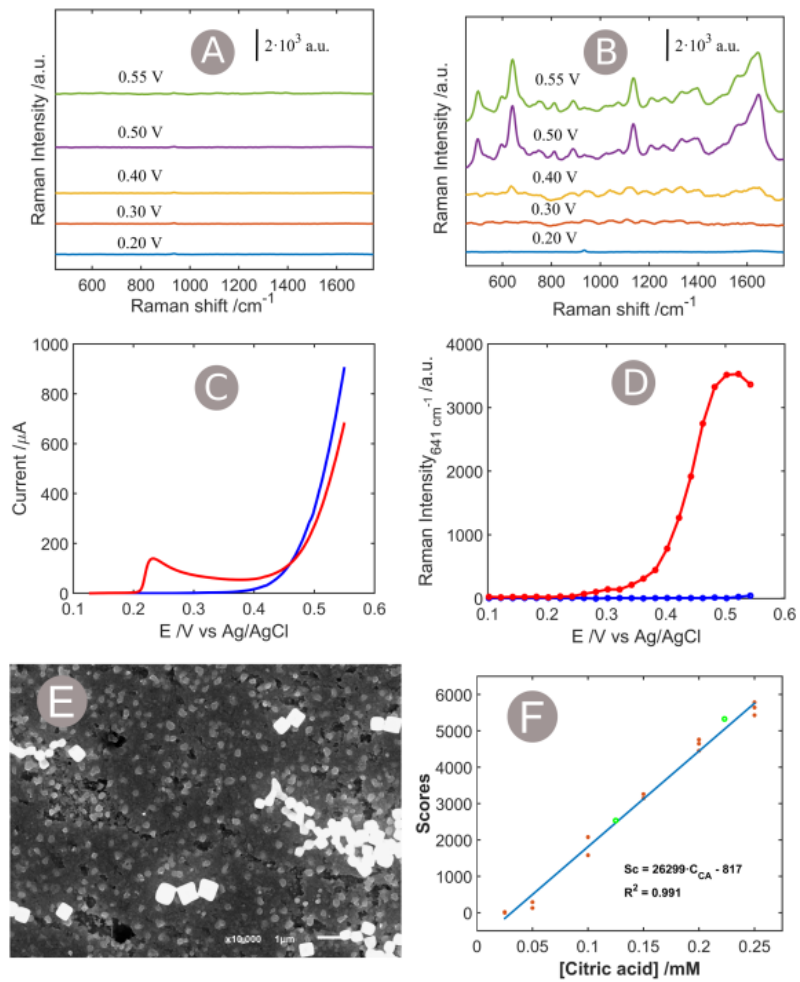

Fig. 12. Raman spectra for UA $0.2 \mathrm{mM}$ in (a) $\mathrm{HClO}_{4} 0.1 \mathrm{M}$ and (b) $\mathrm{HClO}_{4} 0.1 \mathrm{M}+\mathrm{KCl} 5 \cdot 10^{-3} \mathrm{M}$ at different electrode potentials during the oxidation of the silver disk electrode. (c) LSV and (d) voltaRamangram at $641 \mathrm{~cm}^{-1}$ as a function of the potential applied for UA $0.2 \mathrm{mM}$ in $\mathrm{HClO}_{4} 0.1 \mathrm{M}$ (blue curve) and UA $0.2 \mathrm{mM}$ in $\mathrm{HClO}_{4} 0.1 \mathrm{M}+\mathrm{KCl} 5 \cdot 10^{-3} \mathrm{M}$ (red curve). Initial potential: $+0.10 \mathrm{~V}$. Final potential: $+0.55 \mathrm{~V}$. (e) SEM image of the surface at $+0.49 \mathrm{~V}$. (f) Calibration curve for citric acid. Scan rate: $0.02 \mathrm{~V} \cdot \mathrm{s}^{-1}$. Reprinted from Ref. [154]. Copyright 2018, with permission from Elsevier.

Raman-SEC is also very useful to follow the modification of the electrode surface. This technique confirms easily not only such modification but also the possible changes of this modification, as for example, the formation of dimeric structures of thionine layer covalently bound to a solid surface [245] or the reaction products upon self-assembled monolayers reduction. Also, information about compounds adsorbed on the electrode and their transformation can be easily obtained. The interaction of gamma-hydroxybutyric acid (GHB), the cyclic lactone derivative (GBL), 1-butanol and butyric and succinic acids on a polycrystalline platinum electrode in acidic medium was studied using RamanSEC, with GHB and 1-butanol being the only electroactive substances, although some interaction on 
platinum surface is observed for all the molecules by insitu SERS [281]. Other works have shown that the covalent immobilization of redox-active dyes can be an important strategy to evaluate structure-activity relationships in nanoscale electrochemistry by using Raman-SEC of surface-attached dyes, as for example Nile Blue, to SERS substrates [282,283].

The interaction between components of composites in the electrode surface has also been studied. A good example can be found in the study of the interaction between carbon nanotubes and ruthenium purple [284] in the development of thin films that are used as hydrogen peroxide sensors.

Raman-SEC has been successfully used in the study of redox-active proteins immobilized on metallic substrates. The provided information is limited not only to faradaic processes, but it also provides simultaneous insight into structural and orientational parameters [285]. The component analysis of the potential dependent SERS spectra of cytochrome c552 provides the relative spectral contributions of the ferric and ferrous heme c [285]. From Nernst plots, the potential of the redox transition and an apparent number of transferred electrons for the immobilized cyt c552 were obtained.

Living neural PC12 cells have also been studied [286]. SERS and linear sweep voltammetry were combined to analyze the intracellular and extracellular state available for both bulk and single PC12 cells. In this way, the changes in the biochemical composition could be observed during the redox processes. This work shows that the cell lysates were shown to behave differently, compared to living PC12 cells. Raman-SEC can be applied for sensitive in-vitro drug screening with multiple detection and high sensitivity, being a non-invasive and non-destructive tool for cellular researches.

Raman-SEC has been used to study the modification of a nanostructured Au electrode with a 4-mercaptopyridine (MPy) self-assembled monolayer and subsequent addition of hemin to the MPy surface [242]. In this way, because of the SERS effect, a few thousands of molecules can be detected, obtaining important information about the shift of frequencies with the oxidation state.

From the bands observed in the Raman spectra, SEC can provide information about the orientation of the molecules on the electrode as a function of the potential [243].

In the case of the electrochemical modification of electrodes with plasmonic NPs, Raman-SEC can be used to in-situ monitor the SERS properties of the NPs during the electrodeposition process by using a probe molecule such as cyanide, EDTA, etc. [287].
An interesting recent approach for analytical SEC is based on plasmonic liquid marbles that were exploited as a bifunctional SERS platform and working electrode for redox process modulation, allowing the study of microliter reactions [288].

Van Duyne et al. have proposed a dual excitationwavelength SERS approach [289] that was used to resolve the spectral changes between the R6G cation and neutral radical. In this way, a more sensitive monitoring of electrochemical reactions with Raman-SEC is obtained due to the ability to observe both oxidized and reduced species simultaneously.

\section{Challenges}

A single time-resolved SEC experiment yields a huge amount of information. For example, a UV/Vis absorption SEC experiment, using cyclic voltammetry (CV), scanning a potential window of $1 \mathrm{~V}$ at a potential scan rate of $0.010 \mathrm{~V} \cdot \mathrm{s}^{-1}$ and using a spectroscopic time acquisition of $100 \mathrm{~ms}$ with a diode array of 1044 elements, provides a data matrix of 2000x1044 absorbance values that are hardly managed using popular spreadsheet applications. Therefore, neither the complex experimental setup nor the complex mathematical analysis of the results helped to make popular this set of powerful techniques, particularly for quantitative analysis. However, the results obtained using SEC are really remarkable, providing information in a direct way that can be hardly extracted from only an electrochemical experiment.

Therefore, these techniques are quite interesting for users, but they must be simplified to be used. Most of SEC works have been performed using "homemade" instrumental setups. Remarkably, during the last years, a number of companies have commercialized spectroelectrochemistry instruments. Some of these new experimental solutions not only include all the experimental setup to perform the experiments, which can be customized, but also the software to manage the complex data sets in a simple way. Commercial instruments for UV/Vis-SEC and Raman-SEC include the potentiostat, the light source and the spectrometer in the same box. Moreover, the instruments are controlled by software developed on purpose to perform and analyze SEC experiments. Therefore, anyone interested in these techniques will be able to perform experiments and to analyze the results in a simple way. Thus, we can expect a higher number of new SEC users in the next years which will induce the development of innovative applications. 
Technological developments have been amazing during the last years. Both the instruments and the data analysis have been largely improved. For example, optical fibers, low cost monochromators, faster and more sensitive CCD detectors and powerful computers have allowed the development of SEC instruments in which the data are obtained as fast as in an electrochemical setup. Moreover, the economic cost of the instrumentation has decreased in a significant way. Therefore, SEC is not only more powerful but also much simpler and cheaper than years ago. Any researcher can carry out SEC experiments that were almost impossible to be performed a few years ago. Furthermore, the reproducibility of the experiments is remarkable [43]. The mathematical analysis of the fullspectra obtained along the electrochemical experiment was also very difficult. Just exporting data was too complex for a non-expert user. For these reasons, most researchers in SEC worked either using fixed potentials or using only one wavelength to analyze the experiments. Sometimes, only a point contains all the important information about a sample, but usually it only occurs in simple problems. Now, data analysis can be performed in a simple way in seconds. And surely, a number of multivariate mathematical functions (e.g. principal component analysis, partial least squares, PARAFAC, etc.) will be included in spectroelectrochemistry commercial software in a very near future. A SEC experiment provides thousands of points containing chemical information. Therefore, it is important to develop mathematical tools to use all this information to solve complex analytical problems. Machine learning [290], neural networks [291], wavelets [292] and many other mathematical tools will help to increase the potential applications of all the SEC techniques. Particularly, in the case of Raman-SEC, users have to look for new mathematical tools to avoid the influence of the baseline in the spectral response. Analysis of a single Raman spectrum is quite simple, but when hundreds of spectra are obtained during a single experiment, the calculation of the baseline for the full spectrum can be a challenge that has to be mathematically addressed in the next years. A well estimated baseline is basic for a good analytical quantification. Also, the development of mathematical functions to deconvolve a Raman peak that is evolving during the SEC experiment in the different Raman bands that are overlapped would be a very powerful tool for a better understanding of the electrochemical processes.

Improvement in the preparation of SERS substrates to obtain analytical measurements with high reproducibility is one of the main challenges in Raman-SEC. If this point is addressed, Raman-SEC will take off as one of the best analytical techniques to study complex mixtures in fast experiments.

In the case of PL-SEC, the development of a simple and reproducible PL-SEC device for quantitative analysis is still a challenge that must be resolved, because assembling most of the experimental setups is timeconsuming.

As in many instrumental techniques, limits of detection in SEC depend strongly on the properties of the analytes. Molar absorption coefficients, quantum yields or cross sections imply a limitation for the analytes, but the development of instrumentation should help to improve the limits of detection. Better light sources, optical fibers and detectors should help to increase the $\mathrm{S} / \mathrm{N}$ ratio, and therefore, to achieve better limits of detection in all the SEC techniques.
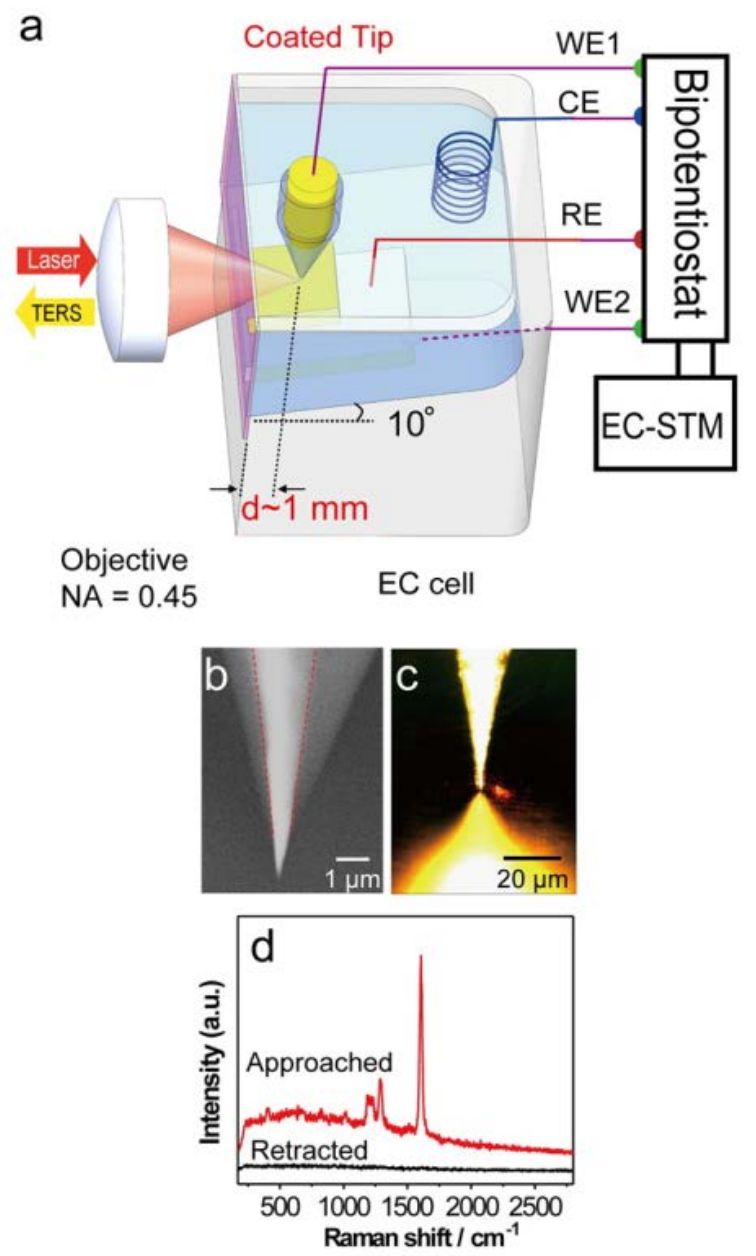

Fig. 13. (a) Schematic illustration of the EC-TERS setup. (b) SEM image of an insulated gold tip. (c) Microscopic image of the tip, single-crystal substrate, and laser spot in an EC-TERS system. (d) TERS of 4-PBT adsorbed on the Au(111) surface obtained while the tip was approached (top) and retracted (bottom). The acquisition time was $1 \mathrm{~s}$. The bias voltage was $500 \mathrm{mV}$, and the tunneling current was $500 \mathrm{pA}$. Adapted with permission from Ref. [299]. Copyright 2015, American Chemical Society. 
Combination of more than one spectroscopic technique should provide much more information on the electrode process, and therefore on the analytical method. Recently, the combination of Raman-SEC and UV/Vis-SEC in parallel mode has been reported [226], yielding concomitantly information about the electrochemistry of compounds in solution and about the electrode surface. Schumann et al. [293] have coupled scanning electrochemical microscopy (SECM) with SERS microscopy to characterize local surface modifications. Hopefully, not only these combinations but many others could be developed in the next years, which should improve the selectivity of the analytical method.

Development of electrochemical tip-enhanced Raman spectroscopy (EC-TERS) is going to be fundamental to study electrochemical phenomena at the real nanoscale, Fig. 13. The first examples of EC-TERS are providing very interesting results [148,294-299]. A great effort must be made to develop simpler experimental setups and to produce very reproducible tips. If these challenges are addressed, EC-TERS will become one of the best techniques for surface electrochemistry.

A very interesting approach in quantitative Raman-SEC will be the use of a new method for SERS that is based on the use of shell isolated nanoparticle-enhanced Raman spectroscopy (SHINERS) [115,227-229,300-302], Fig. 14. SHINERS allows researchers to use any kind of material for the electrode surface. In this way, it will be possible to remove any limitation in the preparation of the electrodes.

Finally, we can finish this review stating that the major challenge for SEC is to increase its number of users. Undoubtedly, users are the main factor to extract all the potential of these techniques. Creativity of scientists to improve the sensitivity and selectivity based on chemical, physical and mathematical knowledge will yield the best future for spectroelectrochemistry.

In this regard, it is important to mention a large number of researchers that have contributed to the development and use of SEC for many years. As the reader will know, it is impossible to include all references about their works in this review. We feel necessary to mention most of these researchers because their works about SEC deserve to be read by people interested in the use of this technique. For this reason we would like to highlight and thank, in alphabetic order, the inspiring works of J.L. Anderson, R.L. Birke, D. Bizzotto, H.N. Blount, B. Bozzini, G. Cheng, S. Dong, L. Dunsch, D.J. Fermín, W. Fiedler, M. Fleischmann, P.A. Flowers, D.R. Gamelin, H. Girault, A. Gopalan, P. Guyot-Sionnest, W.R. Heineman, R. Holze, A.J. Houtepen, A. Ivaska, T. Iwasita, K. Kadish, W. Kaim, M. Kalbac, L. Kavan, V.I. Klimov, T.
Kuwana, J.R. Lombardi, J. López-Palacios, A. Malinauskas, R. Marassi, M. Marcaccio, R.L. McCreery, F. Miomandre, R.W. Murray, P. Mulvaney, H. Nagatani, L. Nie, M. Osawa, F. Paolucci, S.M. Park, J.E. Pemberton, B. Pettinger, S. Pons, M.D. Porter, P. Rapta, B. Ren, B. Sarkar, D.A. Scherson, C.J. Seliskar, N. Sojic, J.W. Strojek, Z.Q. Tian, L. Toppare, J.F. Tyson, R.P. Van Duyne, M.J. Weaver, W. Wei, Q. Xie, S. Yao, J. Zak, all their collaborators, and many other that we may have unintentionally forgotten.

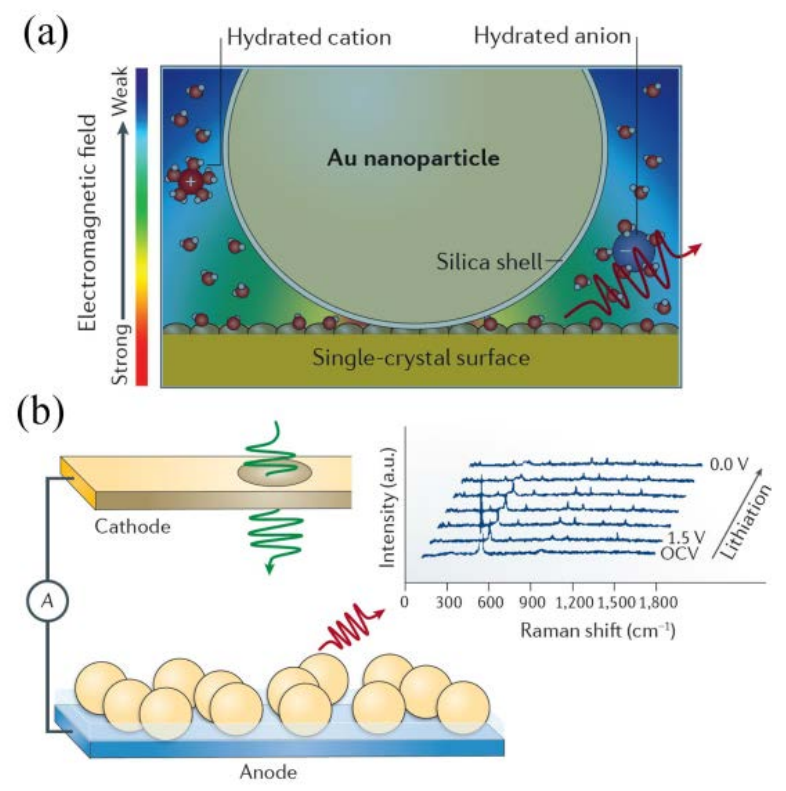

Fig. 14. (a) Schematic illustration of shell-isolated nanoparticles at an atomically flat single-crystal surface and in situ monitoring of surface electrooxidation of Au(hkl) surfaces. (b) In situ shell-isolated nanoparticle-enhanced Raman spectroscopy (SHINERS) study of solid electrolyte interphase formation on the surface of a Si electrode in a Li ion battery. The shell-isolated nanoparticles (Au@SiO2) were deposited on the electrode surface before the assembly of the coin cell. A small hole was made through the top cap, Li foil and separator for the laser to enter and the Raman signal to exit the cell. Reprinted by permission from Springer Nature: Nature Reviews Materials from ref. [115], Copyright 2016.

\section{Acknowledgements}

Authors acknowledge the financial support from Ministerio de Economía y Competitividad (Grants CTQ2017-83935-RAEI/FEDERUE) and Junta de Castilla y León (Grant BU033-U16 and BU297P18). J. G-R.. thanks UBU for his postdoctoral contract. J.V.P-R. thanks JCyL for his postdoctoral fellowship (Grant BU033-U16). Thanks to J. López-Palacios, because he started to work in spectroelectrochemistry in a small city like Burgos and he taught us all we know now. 
[24] T. E. Keyes, R. J. Forster, in Handb. Electrochem., Elsevier, 2007, pp. 591-635.

\section{References}

[1] W. R. Heineman, F. M. Hawkridge, H. N. Blount, in Electroanal. Chem. A Ser. Adv. Vol . 13, Marcel Dekker, Inc., New York, 1984.

[2] T. Kuwana, N. Winograd, in Electroanal. Chem. A Ser. Adv. Vol . 7, Marcel Dekker, Inc., New York, 1974.

[3] L. Dunsch, J. Solid State Electrochem. 2011, 15, 16311646.

[4] L. Kavan, L. Dunsch, ChemPhysChem 2011, 12, 47-55.

[5] P. Audebert, F. Miomandre, Chem. Sci. 2013, 4, 575-584.

[6] U. Bussy, M. Boujtita, Talanta 2015, 136, 155-160.

[7] K. J. Lee, N. Elgrishi, B. Kandemir, J. L. Dempsey, Nat. Rev. Chem. 2017, 1, 0039.

[8] Y. Zhai, Z. Zhu, S. Zhou, C. Zhu, S. Dong, Nanoscale 2018, 10, 3089-3111.

[9] L. León, J. D. Mozo, TrAC Trends Anal. Chem. 2018, 102, 147-169.

[10] D. Bizzotto, Curr. Opin. Electrochem. 2018, 7, 161171.

[11] F. Miomandre, P. Audebert, Luminescence in Electrochemistry, Springer International Publishing, Cham, 2017.

[12] L. Kavan, L. Dunsch, ChemPhysChem 2007, 8, 974 998.

[13] W. R. Heineman, Anal. Chem. 1978, 50, 390A-402A.

[14] W. Plieth, G. S. Wilson, C. G. de la Fe, Pure Appl. Chem. 1998, 70, 1395-1414.

[15] D.-Y. Wu, J.-F. Li, B. Ren, Z.-Q. Tian, Chem. Soc. Rev. 2008, 37, 1025.

[16] J. A. Crayston, in Compr. Coord. Chem. II, Elsevier, 2003, pp. 775-789.

[17] J. A. Crayston, in Encycl. Electrochem., Wiley-VCH Verlag GmbH \& Co. KGaA, Weinheim, Germany, 2007.

[18] R. C. Alkire, D. M. Kolb, J. Lipkowski, P. N. Ross, Advances in Electrochemical Science and Engineering, Wiley-VCH Verlag GmbH, Weinheim, Germany, 2006.

[19] D. A. Scherson, Y. V. Tolmachev, I. C. Stefan, in Encycl. Anal. Chem., John Wiley \& Sons, Ltd, Chichester, UK, 2006.

[20] W. R. Heineman, J. Chem. Educ. 1983, 60, 305-308.

[21] R. J. Gale, Spectroelectrochemistry, Springer US, Boston, MA, 1988.

[22] R. O. Lezna, N. R. de Tacconi, Anal. Chem. 1992, 64, 429A-441A.

[23] J. Niu, S. Dong, Rev. Anal. Chem. 1996, 15, 1-171.
[25] Y. Dai, G. M. Swain, M. D. Porter, and J. Zak, Anal. Chem. 2008, 80, 14-22.

[26] W. Kaim, J. Fiedler, Chem. Soc. Rev. 2009, 38, 337382.

[27] D. L. Jeanmaire, M. R. Suchanski, R. P. Van Duyne, J. Am. Chem. Soc. 1975, 97, 1699-1707.

[28] D. L. Jeanmaire, R. P. Van Duyne, J. Am. Chem. Soc. 1976, 98, 4029-4033.

[29] Á. I. López-Lorente, C. Kranz, Curr. Opin. Electrochem. 2017, 5, 106-113.

[30] A. Cuesta, G. Cabello, M. Osawa, C. Gutiérrez, ACS Catal. 2012, 2, 728-738.

[31] G. Samjeské, M. Osawa, Angew. Chemie Int. Ed. 2005, 44, 5694-5698.

[32] D. H. Murgida, P. Hildebrandt, Phys. Chem. Chem. Phys. 2005, 7, 3773-3784.

[33] V. Nedelkovski, A. Schwaighofer, C. A. Wraight, C. Nowak, R. L. C. Naumann, J. Phys. Chem. C 2013, 117, 16357-16363.

[34] J. V. Perales-Rondón, C. Busó-Rogero, J. SollaGullón, E. Herrero, J. M. Feliu, J. Electroanal. Chem. 2017, 800, 82-88.

[35] S. Klod, K. Haubner, E. Jähne, L. Dunsch, Chem. Sci. 2010, 1, 743-750.

[36] S. Klod, F. Ziegs, L. Dunsch, Anal. Chem. 2009, 81, 10262-10267.

[37] R. Boisseau, U. Bussy, P. Giraudeau, M. Boujtita, Anal. Chem. 2015, 87, 372-375.

[38] X. Zhang, J. W. Zwanziger, J. Magn. Reson. 2011, 208, 136-147.

[39] R. D. Webster, Anal. Chem. 2004, 76, 1603-1610.

[40] N. González-Diéguez, A. Colina, J. López-Palacios, A. Heras, Anal. Chem. 2012, 84, 9146-9153.

[41] K. Asadpour-Zeynali, S. Maryam Sajjadi, F. Taherzadeh, Spectrochim. Acta Part A Mol. Biomol. Spectrosc. 2016, 153, 674-680.

[42] J. Garoz-Ruiz, A. Heras, A. Colina, Anal. Chem. 2017, 89, 1815-1822.

[43] J. Garoz-Ruiz, C. Guillen-Posteguillo, A. Colina, A. Heras, Talanta 2019, 195, 815-821.

[44] L. K. Morris, C. J. Seliskar, W. R. Heineman, A. S. Del Negro, S. A. Bryan, Electroanalysis 2009, 21, 20912098.

[45] R. A. Wilson, C. J. Seliskar, G. Talaska, W. R. Heineman, Anal. Chem. 2011, 83, 3725-3729.

[46] D. Martín-Yerga, A. Pérez-Junquera, M. B. GonzálezGarcía, D. Hernández-Santos, P. Fanjul-Bolado, Anal. Chem. 2018, 90, 7442-7449. 
[47] T. S. Pinyayev, C. J. Seliskar, W. R. Heineman, Anal. Chem. 2010, 82, 9743-9748.

[48] A. M. Lines, J. D. Warner, W. R. Heineman, S. B. Clark, S. A. Bryan, Electroanalysis 2018, 30, 2644-2652.

[49] D. Martín-Yerga, A. Pérez-Junquera, M. B. GonzálezGarcía, J. V. Perales-Rondon, A. Heras, A. Colina, D. Hernández-Santos, P. Fanjul-Bolado, Electrochim. Acta 2018, 264, 183-190.

[50] D. Martín-Yerga, A. Pérez-Junquera, D. HernándezSantos, P. Fanjul-Bolado, Electroanalysis 2018, 30, 10951099.

[51] L. Zhao, J. Blackburn, C. L. Brosseau, Anal. Chem. 2015, 87, 441-447.

[52] M. Tsai, Y. Lin, S. Luo, ACS Appl. Mater. Interfaces 2019, 11, 1402-1410.

[53] T. Kuwana, W. R. Heineman, Acc. Chem. Res. 1976, 9, 241-248.

[54] P. M. Usov, C. F. Leong, B. Chan, M. Hayashi, H. Kitagawa, J. J. Sutton, K. C. Gordon, I. Hod, O. K. Farha, J. T. Hupp, M. Addicoat, A. B. Kuc, T. Heine, D. M. D’Alessandro, Phys. Chem. Chem. Phys. 2018, 20, 2577225779.

[55] K. Kholin, M. Valitov, V. Burilov, E. Tselischeva, S. Strekalova, A. Mustafina, Y. Budnikova, M. Kadirov, Electrochim. Acta 2015, 182, 212-216.

[56] T. Shtoyko, D. Stuart, H. N. Gray, J. Chem. Educ. 2007, 84, 1467-1470.

[57] M. C. Figueiredo, I. Ledezma-Yanez, M. T. M. Koper, ACS Catal. 2016, 6, 2382-2392.

[58] D. Izquierdo, V. Ferraresi-Curotto, A. Heras, R. PisDiez, A. C. Gonzalez-Baro, A. Colina, Electrochim. Acta 2017, 245, 79-87.

[59] Z. Liang, M. Kang, G. F. Payne, X. Wang, R. Sun, ACS Appl. Mater. Interfaces 2016, 8, 17478-17488.

[60] W. Chen, J.-J. Chen, R. Lu, C. Qian, W.-W. Li, H.-Q. $\mathrm{Yu}$, Bioelectrochemistry 2014, 98, 103-108.

[61] F. J. Vidal-Iglesias, J. Solla-Gullón, J. M. Orts, A. Rodes, J. M. Pérez, J. Phys. Chem. C 2015, 119, 1231212324.

[62] J. Dong, X. Zhang, V. Briega-Martos, X. Jin, J. Yang, S. Chen, Z.-L. Yang, D.-Y. Wu, J. M. Feliu, C. T. Williams, Z.-Q. Tian, J.-F. Li, Nat. Energy 2019, 4, 60-67.

[63] A. Heras, A. Colina, V. Ruiz, J. López-Palacios, Electroanalysis 2003, 15, 702-708.

[64] J. López-Palacios, A. Heras, Á. Colina, V. Ruiz, Electrochim. Acta 2004, 49, 1027-1033.

[65] S. Garreau, G. Louarn, J. P. Buisson, G. Froyer, S. Lefrant, Macromolecules 1999, 32, 6807-6812.

[66] J. López-Palacios, E. Muñoz, M. A. Heras, Á. Colina, V. Ruiz, Electrochim. Acta 2006, 52, 234-239.
[67] V. Ruiz, Á. Colina, A. Heras, J. López-Palacios, R. Seeber, Electrochem. Commun. 2002, 4, 451-456.

[68] B. Zanfrognini, A. Colina, A. Heras, C. Zanardi, R. Seeber, J. López-Palacios, Polym. Degrad. Stab. 2011, 96, 2112-2119.

[69] V. Ruiz, Á. Colina, A. Heras, J. López-Palacios, Electrochim. Acta 2004, 50, 59-67.

[70] L. Pigani, A. Heras, Á. Colina, R. Seeber, J. LópezPalacios, Electrochem. Commun. 2004, 6, 1192-1198.

[71] F. J. Knorr, J. L. McHale, J. Phys. Chem. C 2013 $117,13654-13662$.

[72] X. Xiong, M. Forster, J. D. Major, Y. Xu, A. J. Cowan, J. Phys. Chem. C 2017, 121, 22073-22080.

[73] G. F. Samu, R. A. Scheidt, P. V. Kamat, C. Janáky, Chem. Mater. 2018, 30, 561-569.

[74] S. Kämper, A. Paretzki, J. Fiedler, S. Záliš, W. Kaim, Inorg. Chem. 2012, 51, 2097-2104.

[75] D. Baran, A. Balan, S. Celebi, B. Meana Esteban, H. Neugebauer, N. S. Sariciftci, L. Toppare, Chem. Mater. 2010, 22, 2978-2987.

[76] S. Goswami, A. J. Matula, S. P. Rath, S. Hedström, S. Saha, M. Annamalai, D. Sengupta, A. Patra, S. Ghosh, H. Jani, S. Sarkar, M. R. Motapothula, C. A. Nijhuis, J. Martin, S. Goswami, V. S. Batista, T. Venkatesan, Nat. Mater. 2017, 16, 1216-1224.

[77] R. Kumar, R. G. Pillai, N. Pekas, Y. Wu, R. L. McCreery, J. Am. Chem. Soc. 2012, 134, 14869-14876.

[78] K. Łępicka, P. Pieta, A. Shkurenko, P. Borowicz, M. Majewska, M. Rosenkranz, S. Avdoshenko, A. A. Popov, W. Kutner, J. Phys. Chem. C 2017, 121, 16710-16720.

[79] G. G. Rodríguez-Calero, S. Conte, M. A. Lowe, S. E. Burkhardt, J. Gao, J. John, K. Hernández-Burgos, H. D. Abruña, J. Electroanal. Chem. 2016, 765, 65-72.

[80] F. W. Richey, B. Dyatkin, Y. Gogotsi, Y. A. Elabd, J. Am. Chem. Soc. 2013, 135, 12818-12826.

[81] V. Ruiz, A. Colina, A. Heras, J. López-Palacios, Small 2006, 2, 56-58.

[82] C. Fernández-Blanco, Á. Colina, A. Heras, Sensors 2013, 13, 5700-5711.

[83] C. Fernández-Blanco, A. Colina, A. Heras, V. Ruiz, J. López-Palacios, Electrochem. Commun. 2012, 18, 8-11.

[84] V. Ruiz, A. Colina, M. Heras, J. Lope-Palacios, Electrochem. Commun. 2006, 8, 863-868.

[85] P. V. Kamat, S. Barazzouk, S. Hotchandani, Angew. Chemie Int. Ed. 2002, 41, 2764-2767.

[86] D. Paolucci, M. M. Franco, M. Iurlo, M. Marcaccio, M. Prato, F. Zerbetto, A. Pénicaud, F. Paolucci, J. Am. Chem. Soc. 2008, 130, 7393-7399.

[87] M. Kalbac, A. Reina-Cecco, H. Farhat, J. Kong, L. Kavan, M. S. Dresselhaus, ACS Nano 2010, 4, 6055-6063. 
[88] D. Ibañez, E. C. Romero, A. Heras, A. Colina, Electrochim. Acta 2014, 129, 171-176.

[89] A. Colina, V. Ruiz, A. Heras, E. Ochoteco, E. Kauppinen, J. López-Palacios, Electrochim. Acta 2011, 56, 1294-1299.

[90] O. Diaz-Morales, T. J. P. Hersbach, D. G. H. Hetterscheid, J. N. H. Reek, M. T. M. Koper, J. Am. Chem. Soc. 2014, 136, 10432-10439.

[91] H. Nagatani, R. A. Iglesias, D. J. Fermín, P.-F. Brevet, H. H. Girault, J. Phys. Chem. B 2000, 104, 6869-6876.

[92] Z. Ding, D. J. Fermín, P.-F. Brevet, H. H. Girault, J. Electroanal. Chem. 1998, 458, 139-148.

[93] A. Martínez, A. Colina, R. A. W. Dryfe, V. Ruiz, Electrochim. Acta 2009, 54, 5071-5076.

[94] D. Ibañez, D. Plana, A. Heras, D. J. Fermín, A. Colina, Electrochem. Commun. 2015, 54, 14-17.

[95] D. Izquierdo, A. Martinez, A. Heras, J. LopezPalacios, V. Ruiz, R. A. W. Dryfe, A. Colina, Anal. Chem. 2012, 84, 5723-5730.

[96] F. Vega Mercado, R. A. Fernández, R. A. Iglesias, S. A. Dassie, Electrochim. Acta 2019, 299, 430-440.

[97] M. Stolar, J. Borau-Garcia, M. Toonen, T. Baumgartner, J. Am. Chem. Soc. 2015, 137, 3366-3371.

[98] C. J. Dahlman, Y. Tan, M. A. Marcus, D. J. Milliron, J. Am. Chem. Soc. 2015, 137, 9160-9166.

[99] P. A. Ash, K. A. Vincent, Chem. Commun. 2012, 48, 1400-1409.

[100] E. L. D’Antonio, E. F. Bowden, S. Franzen, J. Electroanal. Chem. 2012, 668, 37-43.

[101] A. Nakamura, T. Suzawa, Y. Kato, T. Watanabe, Plant Cell Physiol. 2011, 52, 815-823.

[102] J.-B. He, Y. Wang, N. Deng, X.-Q. Lin, Bioelectrochemistry 2007, 71, 157-163.

[103] K. Reybier, T. H. Y. Nguyen, H. Ibrahim, P. Perio, A. Montrose, P.-L. Fabre, F. Nepveu, Bioelectrochemistry 2012, 88, 57-64.

[104] S. N. Syed, H. Schulze, D. Macdonald, J. Crain, A. R. Mount, T. T. Bachmann, J. Am. Chem. Soc. 2013, 135, 5399-5407.

[105] S. H. Kim, J. W. Lee, I.-H. Yeo, Electrochim. Acta 2000, 45, 2889-2895.

[106] X. Liu, Z. Zhang, G. Cheng, S. Dong, Electroanalysis 2003, 15, 103-107.

[107] J. Chen, R. F. Winter, Chem. - A Eur. J. 2012, 18, 10733-10741.

[108] C. Zong, C.-J. Chen, M. Zhang, D.-Y. Wu, B. Ren, J. Am. Chem. Soc. 2015, 137, 11768-11774.

[109] W. Zhang, A. Vivoni, J. R. Lombardi, R. L. Birke, J. Phys. Chem. 1995, 99, 12846-12857.
[110] C. Shi, W. Zhang, R. L. Birke, D. K. Gosser, J. R. Lombardi, J. Phys. Chem. 1991, 95, 6276-6285.

[111] C. Shi, W. Zhang, R. L. Birke, J. R. Lombardi, J. Phys. Chem. 1990, 94, 4766-4769.

[112] A. Kudelski, Talanta 2008, 76, 1-8.

[113] B. Theory, in Mod. Raman Spectrosc. - A Pract. Approach, John Wiley \& Sons, Ltd, Chichester, UK, 2005, pp. 1-21.

[114] S. Schlücker, Angew. Chemie Int. Ed. 2014, 53, 47564795.

[115] S.-Y. Ding, J. Yi, J.-F. Li, B. Ren, D.-Y. Wu, R. Panneerselvam, Z.-Q. Tian, Nat. Rev. Mater. 2016, 1, 16021-16036.

[116] S.-Y. Ding, E.-M. You, Z.-Q. Tian, M. Moskovits, Chem. Soc. Rev. 2017, 46, 4042-4076.

[117] B. Sharma, R. R. Frontiera, A. Henry, E. Ringe, R. P. Van Duyne, Mater. Today 2012, 15, 16-25.

[118] D. Han, G. M. Crouch, K. Fu, L. P. Zaino III, P. W Bohn, Chem. Sci. 2017, 8, 5345-5355.

[119] R. Godin, G. Cosa, J. Phys. Chem. C 2016, 120, 15349-15353.

[120] W. R. Heineman, B. J. Norris, J. F. Goelz, Anal. Chem. 1975, 47, 79-84.

[121] R. W. Murray, W. R. Heineman, G. W. O’Dom, Anal. Chem. 1967, 39, 1666-1668.

[122] J.-S. Yu, C. Yang, H.-Q. Fang, Anal. Chim. Acta 2000, 420, 45-55.

[123] P. A. Flowers, D. A. Blake, Anal. Chem. 2013, 85 3059-3063.

[124] D. Daniel, I. G. R. Gutz, Electroanalysis 2001, 13, 681-685.

[125] C. A. Schroll, S. Chatterjee, W. R. Heineman, S. A. Bryan, Electroanalysis 2012, 24, 1065-1070.

[126] J. Garoz-Ruiz, A. Heras, S. Palmero, A. Colina, Anal. Chem. 2015, 87, 6233-6239.

[127] T. Kuwana, R. K. Darlington, D. W. Leedy, Anal. Chem. 1964, 36, 2023-2025.

[128] J. López-Palacios, A. Colina, A. Heras, V. Ruiz, L. Fuente, Anal. Chem. 2001, 73, 2883-2889.

[129] D. Lee, R. L. Donkers, G. Wang, A. S. Harper, R. W. Murray, J. Am. Chem. Soc. 2004, 126, 6193-6199.

[130] J. P. Skully, R. L. McCreery, Anal. Chem. 1980, 52, 1885-1889.

[131] C. H. Pyun, S. M. Park, Anal. Chem. 1986, 58, 251256.

[132] O. Orcajo, E. Ventosa, A. Martínez, Á. Colina, A. Heras, V. Ruiz, J. López-Palacios, J. Electroanal. Chem. 2006, 596, 95-100. 
[133] T. Shtoyko, A. T. Maghasi, J. N. Richardson, C. J. Seliskar, W. R. Heineman, Anal. Chem. 2003, 75, 45854590 .

[134] S. E. Andria, J. N. Richardson, N. Kaval, I. Zudans, C. J. Seliskar, W. R. Heineman, Anal. Chem. 2004, 76, 31393144.

[135] M. Maizels, C. J. Seliskar, W. R. Heineman, Electroanalysis 2000, 12, 1356-1362.

[136] R. Pruiksma, R. L. McCreery, Anal. Chem. 1979, 51, 2253-2257.

[137] J. F. Tyson, Talanta 1986, 33, 51-54.

[138] J. Zak, M. D. Porter, T. Kuwana, Anal. Chem. 1983, 55, 2219-2222.

[139] V. Ruiz, Á. Colina, A. Heras, J. López-Palacios, R. Seeber, Helv. Chim. Acta 2001, 84, 3628-3642.

[140] A. Kumar, C. Zhou, ACS Nano 2010, 4, 11-14.

[141] W. R. Heineman, T. Kuwana, Anal. Chem. 1971, 43, 1075-1078.

[142] B. Pérez-López, A. Merkoçi, Microchim. Acta 2012, $179,1-16$

[143] K. Scida, P. W. Stege, G. Haby, G. A. Messina, C. D. García, Anal. Chim. Acta 2011, 691, 6-17.

[144] A. Walcarius, S. D. Minteer, J. Wang, Y. Lin, A. Merkoçi, J. Mater. Chem. B 2013, 1, 4878-4908.

[145] Richard L. McCreery, Chem. Rev. 2008, 108, 26462687.

[146] T. CamposHernández, A. C. FernándezBlanco, A. T. Williams, M. Velický, H. V Patten, A. Colina, R. A. W. Dryfe, Electroanalysis 2015, 27, 1026-1034.

[147] A. Heras, A. Colina, J. López-Palacios, A. Kaskela, A. G. Nasibulin, V. Ruiz, E. I. Kauppinen, Electrochem. Commun. 2009, 11, 442-445.

[148] G. Goubert, X. Chen, S. Jiang, R. P. Van Duyne, J. Phys. Chem. Lett. 2018, 9, 3825-3828.

[149] N. González-Diéguez, A. Colina, J. López-Palacios, A. Heras, Anal. Chem. 2012, 84, 9146-9153.

[150] P. Shi, D. A. Scherson, Anal. Chem. 2004, 76, 23982400.

[151] P. Shi, I. Fromondi, Q. Shi, Z. Wang, D. A. Scherson, Anal. Chem. 2007, 79, 202-207.

[152] M. A. Pellitero, Á. Colina, R. Villa, F. J. del Campo, Electrochem. Commun. 2018, 93, 123-127.

[153] J. Garoz-Ruiz, C. Guillen-Posteguillo, A. Heras, A. Colina, Electrochem. Commun. 2018, 86, 12-16.

[154] J. V. Perales-Rondon, S. Hernandez, D. Martin-Yerga, P. Fanjul-Bolado, A. Heras, A. Colina, Electrochim. Acta 2018, 282, 377-383.

[155] J. Niu, S. Dong, Electroanalysis 1995, 7, 1059-1062.
[156] J. D. Brewster, J. L. Anderson, Anal. Chem. 1982, 54, 2560-2566.

[157] J. Garoz-Ruiz, D. Izquierdo, A. Colina, S. Palmero, A. Heras, Anal. Bioanal. Chem. 2013, 405, 3593-3602.

[158] Y. Shi, A. F. Slaterbeck, C. J. Seliskar, W. R. Heineman, Anal. Chem. 1997, 69, 3679-3686.

[159] E. A. Abu, S. A. Bryan, C. J. Seliskar, W. R. Heineman, Electroanalysis 2012, 24, 1517-1523.

[160] H. Kuramitz, A. Piruska, H. B. Halsall, C. J. Seliskar, W. R. Heineman, Anal. Chem. 2008, 80, 9642-9648.

[161] T. Okazaki, E. Shiokawa, T. Orii, T. Yamamoto, N. Hata, A. Taguchi, K. Sugawara, H. Kuramitz, Anal. Chem. 2018, 90, 2440-2445.

[162] B. M. Beam, N. R. Armstrong, S. B. Mendes, Analyst 2009, 134, 454-459.

[163] B. Valeur, M. N. Berberan-Santos, Molecular Fluorescence, Wiley-VCH Verlag GmbH \& Co. KGaA, Weinheim, Germany, 2012.

[164] A. Yildiz, P. T. Kissinger, C. N. Reilley, Anal. Chem. 1968, 40, 1018-1024.

[165] F. Miomandre, C. Allain, G. Clavier, J.-F. Audibert, R. B. Pansu, P. Audebert, F. Hartl, Electrochem. Commun. 2011, 13, 574-577.

[166] D. Bizzotto, Y. Yang, J. L. Shepherd, R. Stoodley, J. Agak, V. Stauffer, M. Lathuillière, A. S. Akhtar, E. Chung, J. Electroanal. Chem. 2004, 574, 167-184.

[167] M.-N. Belzile, R. Godin, A. M. Durantini, G. Cosa, J. Am. Chem. Soc. 2016, 138, 16388-16397.

[168] C. Lei, D. Hu, E. J. Ackerman, Chem. Commun. 2008, 7345, 5490-5492.

[169] F. Miomandre, E. Lépicier, S. Munteanu, O. Galangau, J. F. Audibert, R. Méallet-Renault, P. Audebert, R. B. Pansu, ACS Appl. Mater. Interfaces 2011, 3, 690-696.

[170] X. Liu, L. Hu, N. Pan, L. Grimaud, E. Labbé, O. Buriez, J. Delacotte, F. Lemaître, M. Guille-Collignon, Biophys. Chem. 2018, 235, 48-55.

[171] A. Meunier, O. Jouannot, R. Fulcrand, I. Fanget, M. Bretou, E. Karatekin, S. Arbault, M. Guille, F. Darchen, F. Lemaître, C. Amatore, Angew. Chemie Int. Ed. 2011, 50, 5081-5084.

[172] M. Dias, P. Hudhomme, E. Levillain, L. Perrin, Y. Sahin, F.-X. Sauvage, C. Wartelle, Electrochem. Commun. 2004, 6, 325-330.

[173] W.-L. Wang, Y. Min, S.-S. Yu, W. Chen, J.-J. Chen, X.-Y. Liu, H.-Q. Yu, Phys. Chem. Chem. Phys. 2017, 19, 32580-32588.

[174] D. Martín-Yerga, A. Pérez-Junquera, D. HernándezSantos, P. Fanjul-Bolado, Anal. Chem. 2017, 89, 1064910654.

[175] J. Barrera, D. Ibañez, A. Heras, V. Ruiz, A. Colina, J. Phys. Chem. Lett. 2017, 8, 531-537. 
[176] P. K. Dasgupta, I.-Y. Eom, K. J. Morris, J. Li, Anal. Chim. Acta 2003, 500, 337-364.

[177] M. Fleischmann, P. J. Hendra, A. J. McQuillan, Chem. Phys. Lett. 1974, 26, 163-166.

[178] J. Chen, W. Ding, Z. Luo, B. H. Loo, J. Yao, J. Raman Spectrosc. 2016, 47, 623-635.

[179] H. M. Lee, S. M. Jin, H. M. Kim, Y. D. Suh, Phys. Chem. Chem. Phys. 2013, 15, 5276-5287.

[180] A. M. Robinson, S. G. Harroun, J. Bergman, C. L. Brosseau, Anal. Chem. 2012, 84, 1760-1764.

[181] W. Wang, Chem. Soc. Rev. 2018, 47, 2485-2508.

[182] K. A. Willets, Chem. Soc. Rev. 2014, 43, 3854-3864.

[183] Z.-C. Zeng, S. Hu, S.-C. Huang, Y.-J. Zhang, W.-X. Zhao, J.-F. Li, C. Jiang, B. Ren, Anal. Chem. 2016, 88, 9381-9385.

[184] A. Colina, J. López-Palacios, A. Heras, V. Ruiz, L. Fuente, J. Electroanal. Chem. 2003, 553, 87-95.

[185] R. W. Murray, Anal. Chem. 2007, 79, 1765-1765.

[186] R. W. Murray, Annu. Rev. Anal. Chem. 2010, 3, 1-18.

[187] R. Murray, Anal. Chem. 1991, 63, 271A-271A.

[188] L. Ji, A. Friedrich, I. Krummenacher, A. Eichhorn, H. Braunschweig, M. Moos, S. Hahn, F. L. Geyer, O. Tverskoy, J. Han, C. Lambert, A. Dreuw, T. B. Marder, U. H. F. Bunz, J. Am. Chem. Soc. 2017, 139, 15968-15976.

[189] Y. V. Zatsikha, D. B. Nemez, R. L. Davis, S. Singh, D. E. Herbert, A. J. King, C. J. Ziegler, V. N. Nemykin, Chem. - A Eur. J. 2017, 23, 14786-14796.

[190] A. Heras, F. Vulcano, J. Garoz-Ruiz, N. Porcelli, F. Terzi, A. Colina, R. Seeber, C. Zanardi, Sensors 2019, 19, 518.

[191] P. A. Ash, K. A. Vincent, Chem. Commun. 2012, 48, 1400-1409.

[192] T. E. Rosser, E. Reisner, ACS Catal. 2017, 7, 31313141.

[193] M. Krause, D. Kourkoulos, D. González-Abradelo, K. Meerholz, C. A. Strassert, A. Klein, Eur. J. Inorg. Chem. 2017, 2017, 5215-5223.

[194] A. M. Lines, Z. Wang, S. B. Clark, S. A. Bryan, Electroanalysis 2016, 28, 2109-2117.

[195] J. Wang, K. Wang, F.-B. Wang, X.-H. Xia, Nat. Commun. 2014, 5, 5285-5293.

[196] A. J. C. Silva, V. C. Nogueira, T. E. A. Santos, C. J. T. Buck, D. R. Worrall, J. Tonholo, R. J. Mortimer, A. S. Ribeiro, Sol. Energy Mater. Sol. Cells 2015, 134, 122-132.

[197] C. N. Hernández, M. B. G. García, D. H. Santos, M. A. Heras, A. Colina, P. Fanjul-Bolado, Electrochem. Commun. 2016, 64, 65-68.

[198] S. C. Boehme, H. Wang, L. D. A. Siebbeles, D. Vanmaekelbergh, A. J. Houtepen, ACS Nano 2013, 7, 2500-2508.
[199] S. C. Boehme, D. Vanmaekelbergh, W. H. Evers, L. D. A. Siebbeles, A. J. Houtepen, J. Phys. Chem. C 2016, 120, 5164-5173.

[200] L.-X. Qin, W. Ma, D.-W. Li, Y. Li, X. Chen, H.-B. Kraatz, T. D. James, Y.-T. Long, Chem. - A Eur. J. 2011, 17, 5262-5271.

[201] L. Jin, L. Shang, J. Zhai, J. Li, S. Dong, J. Phys. Chem. C 2010, 114, 803-807.

[202] S.-E. Bae, T. S. Jung, Y.-H. Cho, J.-Y. Kim, K. Kwak, T.-H. Park, Inorg. Chem. 2018, 57, 8299-8306.

[203] E. E. Bancroft, H. N. Blount, F. M. Hawkridge, Anal. Chem. 1981, 53, 1862-1866.

[204] Y. Zhangyu, G. Tiande, Q. Mei, Anal. Chem. 1994, 66, 497-502.

[205] J. F. Cerda, C. X. Guzman, H. Zhang, E. J. Amendola, J. D. Castorino, N. Millet, A. L. Fritz, D. N. Houchins, M. H. Roeder, Electrochem. Commun. 2013, 33, 76-79.

[206] R. Ayranci, M. Ak, New J. Chem. 2016, 40, 80538059.

[207] D. Daniel, I. G. R. Gutz, Anal. Chim. Acta 2003, 494, 215-224.

[208] Y. Fang, D. Long, J. Ye, Anal. Chim. Acta 1997, 342, 13-21.

[209] S. D. Bindesri, D. S. Alhatab, C. L. Brosseau, Analyst 2018, 143, 4128-4135.

[210] W. A. Hassanain, E. L. Izake, G. A. Ayoko, Anal. Chem. 2018, 90, 10843-10850.

[211] T. M. do Prado, F. H. Cincotto, S. A. S. Machado, Electrochim. Acta 2017, 233, 105-112.

[212] M. L. Stegemiller, W. R. Heineman, C. J. Seliskar, T. H. Ridgway, S. A Bryan, T. Hubler, R. L. Sell, Environ. Sci. Technol. 2003, 37, 123-130.

[213] M. Maizels, C. J. Seliskar, W. R. Heineman, S. A. Bryan, Electroanalysis 2002, 14, 1345-1352.

[214] W. R. Heineman, C. J. Seliskar, J. N. Richardson, Russ. J. Electrochem. 2003, 39, 884-893.

[215] N. Winograd, T. Kuwana, Anal. Chem. 1971, 43, 755755.

[216] H. N. Blount, N. Winograd, T. Kuwana, J. Phys. Chem. 1970, 74, 3231-3236.

[217] W. Chen, X.-Y. Liu, C. Qian, X.-N. Song, W.-W. Li, H.-Q. Yu, Biosens. Bioelectron. 2015, 64, 25-29.

[218] E. E. Bancroft, J. S. Sidwell, H. N. Blount, Anal. Chem. 1981, 53, 1390-1394.

[219] K. Danzer, L. A. Currie, Pure Appl. Chem. 1998, 70, 993-1014.

[220] R. Bro, Chemom. Intell. Lab. Syst. 1997, 38, 149-171.

[221] R. Bro, Crit. Rev. Anal. Chem. 2006, 36, 279-293. 
[222] C. a Andersson, R. Bro, Chemom. Intell. Lab. Syst. 2000, 52, 1-4.

[223] T. Azzouz, R. Tauler, Talanta 2008, 74, 1201-1210.

[224] R. Tauler, B. Kowalski, S. Fleming, Anal. Chem. 1993, 65, 2040-2047.

[225] R. Tauler, Chemom. Intell. Lab. Syst. 1995, 30, 133146.

[226] D. Ibañez, J. Garoz-Ruiz, A. Heras, A. Colina, Anal. Chem. 2016, 88, 8210-8217.

[227] J. F. Li, Y. F. Huang, Y. Ding, Z. L. Yang, S. B. Li, X. S. Zhou, F. R. Fan, W. Zhang, Z. Y. Zhou, D. Y. Wu, B. Ren, Z. L. Wang, Z. Q. Tian, Nature 2010, 464, 392-395.

[228] T. A. Galloway, L. J. Hardwick, J. Phys. Chem. Lett. 2016, 7, 2119-2124.

[229] G. Cabello, X.-J. Chen, R. Panneerselvam, Z.-Q. Tian, J. Raman Spectrosc. 2016, 47, 1207-1212.

[230] R. A. Timm, E. T. S. G. da Silva, V. C. Bassetto, H. D. Abruña, L. T. Kubota, Electrochim. Acta 2017, 232, 150-155.

[231] Y. Shi, C. J. Seliskar, W. R. Heineman, Anal. Chem. 1997, 69, 4819-4827.

[232] S. E. Ross, C. J. Seliskar, W. R. Heineman, Anal. Chem. 2000, 72, 5549-5555.

[233] M. Swartz, J. Liq. Chromatogr. Relat. Technol. 2010, 33, 1130-1150.

[234] E. Tesařová, A. Heras, Á. Colina, V. Ruiz, I. Švancara, K. Vytřas, J. López-Palacios, Anal. Chim. Acta 2008, 608, 140-146.

[235] S. D. Branch, A. M. Lines, J. Lynch, J. M. Bello, W. R. Heineman, S. A. Bryan, Anal. Chem. 2017, 89, 73247332.

[236] Ł. Krzemiński, L. Ndamba, G. W. Canters, T. J. Aartsma, S. D. Evans, L. J. C. Jeuken, J. Am. Chem. Soc. 2011, 133, 15085-15093.

[237] P. A. Flowers, K. A. Arnett, Spectrosc. Lett. 2007, 40, 501-511.

[238] R. L. McCreery, Raman Spectroscopy for Chemical Analysis, John Wiley \& Sons, Inc., Hoboken, NJ, USA, 2000.

[239] D. Martín-Yerga, A. Pérez-Junquera, M. B. GonzálezGarcía, D. Hernández-Santos, P. Fanjul-Bolado, Chem. Commun. 2018, 54, 5748-5751.

[240] P. G. Etchegoin, E. C. Le Ru, in Surf. Enhanc. Raman Spectrosc., Wiley-VCH Verlag GmbH \& Co. KGaA, Weinheim, Germany, 2010, pp. 1-37.

[241] G. C. Schatz, R. P. Van Duyne, in Handb. Vib. Spectrosc. (Ed.: P.R. Griffiths), John Wiley \& Sons, Ltd, Chichester, UK, 2006, pp. 1-16.

[242] T. Yuan, L. Le Thi Ngoc, J. van Nieuwkasteele, M. Odijk, A. van den Berg, H. Permentier, R. Bischoff, E. T. Carlen, Anal. Chem. 2015, 87, 2588-2592.
[243] D. Ibañez, A. Santidrian, A. Heras, M. Kalbáč, A. Colina, J. Phys. Chem. C 2015, 119, 8191-8198.

[244] J.-F. Li, Y.-J. Zhang, A. V. Rudnev, J. R. Anema, S.B. Li, W.-J. Hong, P. Rajapandiyan, J. Lipkowski, T. Wandlowski, Z.-Q. Tian, J. Am. Chem. Soc. 2015, 137, 2400-2408.

[245] A. Blacha-Grzechnik, K. Piwowar, P. Zassowski, R. Motyka, J. Zak, Electrochim. Acta 2017, 245, 902-911.

[246] T. Kuwana, W. R. Heineman, Bioelectrochemistry Bioenerg. 1974, 1, 389-406.

[247] H. D. Dewald, J. Wang, Anal. Chim. Acta 1985, 166, 163-170.

[248] Q.-J. Xie, L.-H. Nie, S.-Z. Yao, Anal. Sci. 1997, 13, 453-465.

[249] L. E. Fosdick, J. L. Anderson, Anal. Chem. 1988, 60, 163-168.

[250] Q. Xie, X. Cheng, W. Wei, L. Nie, S. Yao, Talanta 1994, 41, 261-267.

[251] M. Feng, D. Long, Y. Fang, Anal. Chim. Acta 1998, 363, 67-73.

[252] N. Alizadeh, A. Ghoorchian, Anal. Chem. 2018, 90, 10360-10368.

[253] T. Shtoyko, J. N. Richardson, C. J. Seliskar, W. R. Heineman, Electrochim. Acta 2005, 50, 3191-3199.

[254] S. E. Andria, C. J. Seliskar, W. R. Heineman, Anal. Chem. 2009, 81, 9599-9606.

[255] J. M. DiVirgilio-Thomas, W. R. Heineman, C. J. Seliskar, Anal. Chem. 2000, 72, 3461-3467.

[256] L. Gao, C. J. Seliskar, Chem. Mater. 1998, 10, 24812489.

[257] J. N. Richardson, A. L. Dyer, M. L. Stegemiller, I. Zudans, C. J. Seliskar, W. R. Heineman, Anal. Chem. 2002, 74, 3330-3335.

[258] Y. Xie, S. Dong, J. Electroanal. Chem. Interfacial Electrochem. 1990, 284, 279-288.

[259] R. Wilson, D. J. Schiffrin, B. J. Luff, J. S. Wilkinson, Sensors Actuators B Chem. 2000, 63, 115-121.

[260] T. Shtokyo, S. Conklin, A. T. Maghasi, J. N. Richardson, A. Piruska, C. J. Seliskar, W. R. Heineman, Anal. Chem. 2004, 76, 1466-1473.

[261] S. E. Andria, J. N. Richardson, N. Kaval, I. Zudans, C. J. Seliskar, W. R. Heineman, Anal. Chem. 2004, 76, 31393144.

[262] S. E. Andria, C. J. Seliskar, W. R. Heineman, Anal. Chem. 2010, 82, 1720-1726.

[263] E. Topoglidis, C. J. Campbell, A. E. G. Cass, J. R. Durrant, Langmuir 2001, 17, 7899-7906.

[264] K. Imai, T. Okazaki, N. Hata, S. Taguchi, K. Sugawara, H. Kuramitz, Anal. Chem. 2015, 87, 2375-2382. 
[265] D. R. Dunphy, S. B. Mendes, S. S. Saavedra, N. R. Armstrong, Anal. Chem. 1997, 69, 3086-3094.

[266] T. Noyhouzer, M. E. Snowden, U. M. Tefashe, J. Mauzeroll, Anal. Chem. 2017, 89, 5246-5253.

[267] D. Daniel, I. G. R. Gutz, J. Pharm. Biomed. Anal. 2005, 37, 281-286.

[268] L. León, J. J. Maraver, J. Carbajo, J. D. Mozo, Sensors Actuators B Chem. 2013, 186, 263-269.

[269] K. Thajee, P. Paengnakorn, W. Wongwilai, K. Grudpan, Talanta 2018, 185, 160-165.

[270] N. Li, Y. Lu, S. Li, Q. Zhang, J. Wu, J. Jiang, G. L. Liu, Q. Liu, Biosens. Bioelectron. 2017, 93, 241-249.

[271] D. Ibañez, C. Fernandez-Blanco, A. Heras, A. Colina, J. Phys. Chem. C 2014, 118, 23426-23433.

[272] J. Garoz-Ruiz, A. Heras, A. Colina, Electrochem. Commun. 2018, 90, 73-77.

[273] J. M. Salverda, A. V. Patil, G. Mizzon, S. Kuznetsova, G. Zauner, N. Akkilic, G. W. Canters, J. J. Davis, H. A. Heering, T. J. Aartsma, Angew. Chemie Int. Ed. 2010, 49, 5776-5779.

[274] S. Cannan, I. Douglas Macklam, P. R. Unwin, Electrochem. Commun. 2002, 4, 886-892.

[275] R. A. Karaballi, A. Nel, S. Krishnan, J. Blackburn, C. L. Brosseau, Phys. Chem. Chem. Phys. 2015, 17, 2135621363.

[276] M. Mohammadniaei, J. Yoon, T. Lee, J.-W. Choi, J. Biotechnol. 2018, 274, 40-46.

[277] T. P. Lynk, O. J. R. Clarke, N. Kesavan, C. L. Brosseau, Sensors Actuators B Chem. 2018, 257, 270-277.

[278] C. N. Hernández, D. Martín-Yerga, M. B. GonzálezGarcía, D. Hernández-Santos, P. Fanjul-Bolado, Talanta 2018, 178, 85-88.

[279] J. V. Perales-Rondon, S. Hernandez, A. Heras, A. Colina, Appl. Surf. Sci. 2019, 473, 366-372.

[280] T. P. Lynk, C. S. Sit, C. L. Brosseau, Anal. Chem. 2018, 90, 12639-12646.

[281] R. Jiménez-Pérez, J. M. Sevilla, T. Pineda, M. Blázquez, J. Gonzalez-Rodriguez, Electrochim. Acta 2016, 193, 154-159.

[282] A. J. Wilson, N. Y. Molina, K. A. Willets, J. Phys. Chem. C 2016, 120, 21091-21098.

[283] A. J. Wilson, K. A. Willets, Analyst 2016, 141, 51445151.

[284] S. Husmann, A. J. G. Zarbin, Dalt. Trans. 2015, 44, 5985-5995.
[285] C. M. Silveira, P. O. Quintas, I. Moura, J. J. G. Moura, P. Hildebrandt, M. G. Almeida, S. Todorovic, PLoS One 2015, 10, e0129940.

[286] W. A. El-Said, T.-H. Kim, Y.-H. Chung, J.-W. Choi, Biomaterials 2015, 40, 80-87.

[287] D. Ibañez, D. Izquierdo, C. Fernandez-Blanco, A. Heras, A. Colina, J. Raman Spectrosc. 2018, 49, 482-492.

[288] C. S. L. Koh, H. K. Lee, G. C. Phan-Quang, X. Han, M. R. Lee, Z. Yang, X. Y. Ling, Angew. Chemie Int. Ed. 2017, 56, 8813-8817.

[289] S. Zaleski, M. F. Cardinal, D. V. Chulhai, A. J. Wilson, K. A. Willets, L. Jensen, R. P. Van Duyne, J. Phys. Chem. C 2016, 120, 24982-24991.

[290] P. H. Rogers, K. D. Benkstein, S. Semancik, Anal. Chem. 2012, 84, 9774-9781.

[291] M. Woldegebriel, E. Derks, Anal. Chem. 2017, 89, 1212-1221.

[292] X.-G. Shao, A. K.-M. Leung, F.-T. Chau, Acc. Chem. Res. 2003, 36, 276-283.

[293] J. Clausmeyer, M. Nebel, S. Grützke, Y. U. Kayran, W. Schuhmann, Chempluschem 2018, 83, 414-417.

[294] Y.-P. Huang, S.-C. Huang, X.-J. Wang, N. Bodappa, C.-Y. Li, H. Yin, H.-S. Su, M. Meng, H. Zhang, B. Ren, Z.L. Yang, R. Zenobi, Z.-Q. Tian, J.-F. Li, Angew. Chemie Int. Ed. 2018, 57, 7523-7527.

[295] X. Wang, S.-C. Huang, T.-X. Huang, H.-S. Su, J.-H. Zhong, Z.-C. Zeng, M.-H. Li, B. Ren, Chem. Soc. Rev. 2017, 46, 4020-4041.

[296] M. Mattei, G. Kang, G. Goubert, D. V. Chulhai, G. C. Schatz, L. Jensen, R. P. Van Duyne, Nano Lett. 2017, 17 590-596.

[297] N. Martín Sabanés, T. Ohto, D. Andrienko, Y. Nagata, K. F. Domke, Angew. Chemie Int. Ed. 2017, 56, 97969801.

[298] A. B. Zrimsek, N. Chiang, M. Mattei, S. Zaleski, M. O. McAnally, C. T. Chapman, A.-I. Henry, G. C. Schatz, R. P. Van Duyne, Chem. Rev. 2017, 117, 7583-7613.

[299] Z.-C. Zeng, S.-C. Huang, D.-Y. Wu, L.-Y. Meng, M.H. Li, T.-X. Huang, J.-H. Zhong, X. Wang, Z.-L. Yang, B. Ren, J. Am. Chem. Soc. 2015, 137, 11928-11931.

[300] J. Li, Z. Tian, in Front. Surface-Enhanced Raman Scatt., John Wiley \& Sons, Ltd, Chichester, UK, 2014, pp. 163-192.

[301] J. R. Anema, J.-F. Li, Z.-L. Yang, B. Ren, Z.-Q. Tian, Annu. Rev. Anal. Chem. 2011, 4, 129-150.

[302] J.-F. Li, Y.-J. Zhang, S.-Y. Ding, R. Panneerselvam, Z.-Q. Tian, Chem. Rev. 2017, 117, 5002-5069. 